AperTO - Archivio Istituzionale Open Access dell'Università di Torino

\title{
Portuguese cacholeira blood sausage: A first taste of its microbiota and volatile organic compounds
}

\section{This is the author's manuscript}

Original Citation:

Availability:

This version is available http://hdl.handle.net/2318/1746825

since 2020-07-29T08:56:48Z

Published version:

DOI:10.1016/j.foodres.2020.109567

Terms of use:

Open Access

Anyone can freely access the full text of works made available as "Open Access". Works made available under a Creative Commons license can be used according to the terms and conditions of said license. Use of all other works requires consent of the right holder (author or publisher) if not exempted from copyright protection by the applicable law. 


\section{Journal Pre-proofs}

Portuguese cacholeira blood sausage: A first taste of its microbiota and volatile organic compounds

Luca Belleggia, Ilario Ferrocino, Anna Reale, Floriana Boscaino, Tiziana Di Renzo, Maria Rita Corvaglia, Luca Cocolin, Vesna Milanović, Federica

Cardinali, Cristiana Garofalo, Francesca Clementi, Lucia Aquilanti, Andrea Osimani

PII:

S0963-9969(20)30592-5

DOI: $\quad$ https://doi.org/10.1016/j.foodres.2020.109567

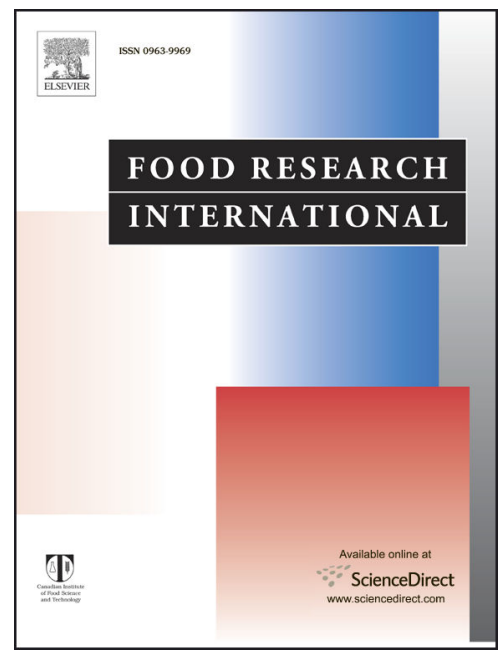

Reference:

FRIN 109567

To appear in:

Food Research International

Received Date: $\quad 1$ April 2020

Revised Date: $\quad 13$ July 2020

Accepted Date: 17 July 2020

Please cite this article as: Belleggia, L., Ferrocino, I., Reale, A., Boscaino, F., Di Renzo, T., Corvaglia, M.R., Cocolin, L., Milanović, V., Cardinali, F., Garofalo, C., Clementi, F., Aquilanti, L., Osimani, A., Portuguese cacholeira blood sausage: A first taste of its microbiota and volatile organic compounds, Food Research International (2020), doi: https://doi.org/10.1016/j.foodres.2020.109567

This is a PDF file of an article that has undergone enhancements after acceptance, such as the addition of a cover page and metadata, and formatting for readability, but it is not yet the definitive version of record. This version will undergo additional copyediting, typesetting and review before it is published in its final form, but we are providing this version to give early visibility of the article. Please note that, during the production process, errors may be discovered which could affect the content, and all legal disclaimers that apply to the journal pertain.

(C) 2020 Published by Elsevier Ltd. 
Portuguese cacholeira blood sausage: a first taste of its microbiota and volatile organic compounds

Luca Belleggia ${ }^{1}$, Ilario Ferrocino ${ }^{2}$, Anna Reale $^{3,}$, Floriana Boscaino ${ }^{3}$, Tiziana Di Renzo ${ }^{3}$, Maria Rita Corvaglia ${ }^{2}$, Luca

Cocolin $^{2}$, Vesna Milanović ${ }^{1}$, Federica Cardinali ${ }^{1}$, Cristiana Garofalo ${ }^{1}$, Francesca Clementi ${ }^{1}$, Lucia Aquilanti ${ }^{1}$, Andrea Osimani $1^{1, *}$

${ }^{1}$ Dipartimento di Scienze Agrarie, Alimentari ed Ambientali, Università Politecnica delle Marche, via Brecce Bianche, Ancona, Italy

${ }^{2}$ Department of Agricultural, Forest, and Food Science, University of Turin, Largo Paolo Braccini 2, Grugliasco, Torino, Italy

${ }^{3}$ Istituto di Scienze dell'Alimentazione, Consiglio Nazionale delle Ricerche, Via Roma 64, 83100, Avellino, Italy

* Corresponding authors:

- Dipartimento di Scienze Agrarie, Alimentari ed Ambientali, Università Politecnica delle Marche, via Brecce Bianche, 60131, Ancona, Italy. E-mail address: a.osimani@univpm.it (AO)

- Istituto di Scienze dell'Alimentazione, Consiglio Nazionale delle Ricerche, Via Roma 64, 83100, Avellino, Italy. E-mail address: anna.reale@isa.cnr.it (AR) 


\section{ABSTRACT}

Among typical Portuguese sausages, the cacholeira blood sausage undoubtedly represents one of the most popular preparations. To the authors' knowledge, a lack of information on both the microbiota and the volatile organic compounds (VOCs) of this blood-containing sausage emerges from the available scientific literature. This study represents the first characterization of physico-chemical, microbiological and volatile traits of Portuguese cacholeira blood sausage. To this end, ready-to-eat cacholeira blood sausages were collected from two production batches manufactured in summer (batch 1) and autumn (batch 2). Viable counts showed active microbial communities mainly composed by lactic acid bacteria, coagulase negative cocci, enterococci and eumycetes. The metataxonomic approach showed a simple bacterial composition, which was dominated by Lactobacillus sakei in both the analyzed batches (1 and 2$)$ considered. Carnobacterium, Enterococcus, Kluyvera, Lactococcus and Serratia were found as minor genera. The mycobiota varied according to the production season. Batch 1 was dominated by Starmerella apicola, Debaryomyces hansenii and Candida tropicalis, whereas batch 2 was dominated by D. hansenii. Moreover, Aspergillus spp., Kurtzmaniella zeylanoides, Saccharomyces cerevisiae, Kurtzmaniella santamariae, Brettanomyces bruxellensis and Pichia kluyveri were detected in both the batches as minority species. Seventy-two volatile compounds were identified, including esters, phenols, terpenoids, acids, alcohols, ketones, aldehydes, lactones, furans, sulphur and nitrogen compounds. Significant differences were seen in the amount of some compounds, as a feasible consequence of differences in the raw materials, artisan production and seasonality.

Keywords: Lactobacillus sakei, Debaryomyces hansenii, Starmerella apicola, mycobiota, volatilome. 


\section{Introduction}

The preservation of meat, through salting and drying, dates to the Egyptians and Sumerians, though records describing the production of sausages are also found in the ancient Greek Era and during the Roman Empire, thus suggesting that in ancient times the production of sausages was already a common practice all over the European continent. In such a welldefined area, the peculiar temperate climate that characterizes the Mediterranean basin allowed the establishment of favorable conditions for the ripening of sausages, which led to the evolvement into admirable food products with inestimable historical and gastronomic value (Leroy et al., 2013). The unique sensory traits of such products are conferred by enzymatic degradation and microbial activities that, in the meat batter, cause physical-chemical modifications and volatile compounds production that strongly characterize the end product. In more detail, Enterobacteriaceae, Pseudomonadaceae, Campylobacter and Brochothrix usually constitute the main components of the early stage sausage microbiota, being present as natural contaminants of meat animal carcasses (Cardinali et al., 2018; Petruzzelli et al., 2014; 2016; Tremonte et al., 2005). As soon as the sausage is produced, the anaerobic conditions that establish in the stuffed meat batter allow the selection of pro-technological microorganisms such as the coagulase negative cocci and lactic acid bacteria (Belleggia et al., 2020).

In Mediterranean countries, including Portugal, numerous PDO (Protected Designation of Origin), PGI (Protected Geographical Indication) and TGS (Traditional Guaranteed Specialty) sausages are produced (Aquilanti, Garofalo, Osimani \& Clementi, 2016) together with local fermented meat-based specialties. In Portuguese rural areas, smoked, fermented or dried sausages are part of the traditional daily diet (Marcos et al. 2016). Most of these products, such as alheira, chouriça, chouriço de carne, chouriço mouro, morcela, linguiça, farinheira, chouriço de sangue, salpicão and cacholeira are still manufactured by small-scale industries or artisan producers without the use of any starter culture. Blood-containing sausages are traditionally produced in different European countries, including Germany (e.g. thuringian blood sausage), Austria (e.g. blood-tongue sausage and black pudding), England (e.g. black pudding), Italy (e.g. Sanganel) and Portugal (e.g. cacholeira, chouriça, morcela, chouriço de sangue, Paio Preto and Chouriço Preto).

Among typical Portuguese sausages, the cacholeira blood sausage undoubtedly represents one of the most popular preparations (Marcos et al., 2016). It can be produced using a different blend of pork meat cuts, liver and other internal organs, and fat finely chopped and beaten into a paste; the preparation also includes a small quantity of the customary blood. Spices (e.g. garlic, cumin, sweet pepper, paprika, etc.), additional ingredients (e.g. wine) and additives can be added. Hence, the meat batter is stuffed into animal bowel casing, blanched in hot water at $85{ }^{\circ} \mathrm{C}$ and/or smoked up to 15 days. The ready-to-eat product has a dark brown color, a semi-soft consistency and a mat or brilliant appearance, depending on the recipe and the manufacturing process (Marcos et al., 2016). On cutting, the marbling of the fats and 
offal can be seen. The cacholeira sausage, typically produced in the Alentejo Region, comprising the districts of Evora, Beja and Portalegre, is generally consumed as an appetizer or used to enrich many typical Alentejan dishes.

As reported by Iacumin, Manzano, Stella, \& Comi (2017), the microorganisms or bacterial spores occurring in the raw bloody meat and fat, and the handling of the product during and after processing, influence the final microbial population harbored by blood-containing sausages. To the authors' knowledge, a lack of information on both the microbiota and the volatile organic compounds (VOCs) of cacholeira blood-containing sausage emerges from the available scientific literature. Hence, the present study was aimed to get a first insight on the bacterial and fungal diversity of ready-to-eat cacholeira blood sausages manufactured by an artisan producer located in the Alentejo Region. To this end, different selective growth media and a metataxonomic approach were applied to the profiling of the sausage microbial populations, whereas VOCs were analyzed by Headspace-Solid Phase MicroExtraction-Gas Chromatography/Mass Spectrometry (HS-SPME-GC/MS).

\section{Materials and methods}

\subsection{Sampling}

Eight samples of ready-to-eat cacholeira blood sausage (Figure 1) were collected from two production batches at an artisan producer located in Portalegre, Alentejo, Portugal. For each batch, four samples were collected 30 days after production. In more detail, samples labelled from $\mathrm{C} 1$ to $\mathrm{C} 4$ were manufactured in a single production process in August 2019 (batch 1, summer production), whereas samples labelled from C5 to C8 were manufactured in a single production process in October 2019 (batch 2, autumn production). Each sample consisted of $200 \mathrm{~g}$ of ready-to-eat sausage produced with the following ingredients: pork meat and fat, blood, salt, garlic, pepper, paprika, and sugars. Neither starter cultures nor preservatives were used. To obtain cacholeira blood sausage, minced meat and fat were first added with blood and spices; after 24 hours of rest at $10{ }^{\circ} \mathrm{C}$, the meat batter was stuffed into pork gut casing and blanched in hot water for 5 min. at about $85^{\circ} \mathrm{C}$. The sausages were finally smoked with holly firewood in a traditional smokehouse for 6 days. No further information on the manufacturing process of the samples was provided by the producer. Ready-to-eat cacholeira blood sausages were finally wrapped into food-grade plastic film and stored at $10{ }^{\circ} \mathrm{C}$. The samples were then collected under sterile conditions and stored at $4{ }^{\circ} \mathrm{C}$ until analyses.

\subsection{Physico-chemical measurements}


The $\mathrm{pH}$ of cacholeira blood sausages was determined at the core of the products using a $\mathrm{pH}$ meter equipped with an HI2031 solid electrode (Hanna Instruments, Padova, Italy). Water activity $\left(\mathrm{a}_{\mathrm{w}}\right)$ was determined in accordance with the ISO 21807:2004 standard method using the Aqualab 4TE apparatus (Meter Group, Pullman, USA). Total titratable acidity (TTA) was measured on 10 g-aliquots of each cacholeira sausage, previously homogenized in $90 \mathrm{~mL}$ of distilled water for $5 \mathrm{~min}$ at $260 \mathrm{rpm}$ using a Stomacher 400 Circulator apparatus (VWR International PBI, Milan, Italy). The results were expressed as the total volume $(\mathrm{mL})$ of a $0.1 \mathrm{~N} \mathrm{NaOH}$ solution used to achieve a fixed endpoint $\mathrm{pH}$ of 8.3. Acetate and lactate concentrations were measured using the Acetic Acid (Acetate Kinase Manual Format) and D-/L-Lactic Acid (D/L-Lactate) test kit (Megazyme, Bray, Ireland), respectively, following the manufacturer's instructions.

Cacholeira blood sausages were also analyzed for: dry matter determined by air drying (AOAC, 950.46); protein, determined by Kjeldahl method (AOAC, 981.10); fat, determined by Soxhlet extraction (AOAC, 991.36); ash, assessed in convection oven (AOAC, 920.153); nitrogen free extracts (NFE), calculated by subtracting protein, fat, and ash contents from the total dry matter.

For each sample, the measurements were performed in duplicate and the results were expressed as the mean \pm standard deviation.

\subsection{Microbiological analyses}

Prior to microbiological analysis, sausage casing was removed under sterile conditions using a sterile scalpel. Ten galiquots of each sample were added with $90 \mathrm{~mL}$ of a sterile peptone water solution $(1 \mathrm{~g} / \mathrm{L}$ of bacteriological peptone, Oxoid, Milan, Italy) and homogenized for $3 \mathrm{~min}$ at $260 \mathrm{rpm}$. Ten-fold serial dilutions were prepared with the same diluent and the following microorganisms were counted onto the opportune selective solid media: i) presumptive lactic acid bacteria on De Man Rogosa and Sharpe (MRS) agar (VWR Prolabo Chemicals, Leuven, Belgium) added with cycloheximide ( $250 \mathrm{mg} / \mathrm{L})$ and incubated at $37^{\circ} \mathrm{C}$ for $48-72 \mathrm{~h}$; ii) coagulase negative cocci on Mannitol Salt Agar (MSA) (VWR Prolabo Chemicals) incubated at $37^{\circ} \mathrm{C}$ for $24-48$ h; iii) Enterobacterales on Violet Red Bile Glucose Agar (VRBGA) (VWR Prolabo Chemicals) incubated at $37^{\circ} \mathrm{C}$ for $24 \mathrm{~h}$; iv) Pseudomonadaceae on Pseudomonas Agar Base (PAB) added with cetrimide-fucidin-cephalosporin (CFC) selective supplement (VWR International, Milan, Italy) and incubated at $30^{\circ} \mathrm{C}$ for $24-48 \mathrm{~h}$; v) enterococci on Slanetz Bartley Agar (SBA) incubated at $37^{\circ} \mathrm{C}$ for $48 \mathrm{~h}$; vi) for counting sulfite-reducing clostridia, homogenates were treated in a water bath at $80^{\circ} \mathrm{C}$ for $10 \mathrm{~min}$ and cooled in iced water. Aliquots $(0.1 \mathrm{~mL})$ of each dilution were spread on Tryptone Sulfite Neomycin (TSN) agar and incubated at $37{ }^{\circ} \mathrm{C}$ for $24 \mathrm{~h}$ under anaerobic conditions using the AnaeroGen 2.5 System (Oxoid); vii) eumycetes on Rose Bengal Chloramphenicol Agar (VWR Prolabo Chemicals) incubated at $25^{\circ} \mathrm{C}$ for $72-96 \mathrm{~h}$. 
The results of viable counts, expressed as the Log of colony forming units (cfu) per gram of sample, were reported as mean value of two biological and three technical replicates \pm standard deviation.

Finally, a miniVIDAS apparatus (Biomerieux, Marcy l'Etoile, France) was used to assess the presence/absence of Listeria monocytogenes and Salmonella spp. through the Enzyme-Linked Fluorescent Assay (ELFA) method, in accordance with the AFNOR BIO 12/11-03/04 and AFNOR BIO 12/16-09/05 standard methods, respectively (Haouet et al., 2017).

\subsection{DNA extraction and sequencing}

A $1.5 \mathrm{~mL}$-aliquot of each sample homogenate (dilution $10^{-1}$ ) prepared as described in section 2.3 was centrifuged for 5 min at $16^{\prime} 000 \mathrm{~g}$ and the obtained cell pellet was stored at $-20^{\circ} \mathrm{C}$ until use. The total microbial DNA was extracted from the cell pellets using an E.Z.N.A. soil DNA kit (Omega Bio-tek, Norcross, GA, USA) following the manufacturer's instructions. The quantity and purity of the extracted DNAs were checked using a Nanodrop ND 1000 (Thermo Fisher Scientific, Wilmington, DE, USA). The extracted DNA was used as template in the PCR assays amplifying the V3-V4 region of the $16 \mathrm{~S}$ rRNA gene and the D1 domain of the 26S rRNA gene using the primers and protocols described by Klindworth et al. (2013) and Mota Gutierrez et al. (2019), respectively. PCR amplicons were cleaned according to Illumina guidelines. The sequencing was performed with a MiSeq Illumina instrument (Illumina).

\subsection{Bioinformatics}

After sequencing, reads were first joined using FLASH with default parameters and reads shorter than 300 bp were discarded through prinseq software. USEARCH was then used for chimera filtering. Clean reads were imported in QIIME software for Operational Taxonomic Unit (OTU) clustering (at 99\% of similarity) and for taxonomy assignment by using the Greengenes database for 16S rRNA gene data and the in-house database from Mota Gutierrez et al. (2019). Taxonomy assignments were manually double checked by using the BLASTn suite tool. 16S and 26S rRNA OTUs tables were rarefied at the lowest number of sequence/samples and imported in R for statistical tests. The OTU table displays genus level, or species level. PICRUSt was used to predict the abundances of inferred KEGG gene families based on 16S rRNA gene sequence data. OTUs were redetermined by using the pick_closed_reference_otus.py script of QIIME 1.9.0, with default parameters at $97 \%$ similarity against the Greengenes database; KEGG orthologs were then collapsed at level 3 of hierarchy. 
Headspace volatiles from each cacholeira blood sausage were analyzed by HS-SPME-GC/MS, using a 7890 Agilent GC system coupled to an Agilent 5975 (Agilent Technologies, Santa Clara, California, USA) inert quadrupole mass spectrometer equipped with a Gerstel MPS2 autosampler (Gerstel, Mülheim, Germany).

For each sample, about $5 \mathrm{~g}$ collected from the core of the sausage, was shredded and placed in a $20 \mathrm{~mL}$ headspace vial. The sample was stirred for $10 \mathrm{~min}$ at $45^{\circ} \mathrm{C}$ to accelerate equilibrium of headspace volatile compounds between the sample and the headspace. Then, volatile compounds extraction was carried out by injecting a $50 / 30 \mu \mathrm{m}$ Divinylbenzene/Carboxen/PolyDiMethylSiloxane (DVB/Carboxen/PDMS) SPME fiber (Supelco, Bellefonte, PA) into the vial and exposing it to the headspace for $40 \mathrm{~min}$ at $45^{\circ} \mathrm{C}$. Afterwards, the SPME fiber was desorbed directly into the injection port of the $\mathrm{GC}$ at $250{ }^{\circ} \mathrm{C}$ for $10 \mathrm{~min}$ in the splitless mode. Volatile compounds were separated using a capillary column HP Innowax (Agilent Technologies) (30 m x 0.25mm id. X $0.50 \mu \mathrm{m}$ film thickness); the carrier gas was helium with a flow of $1 \mathrm{~mL} / \mathrm{min}$. The temperature program of the $\mathrm{GC}$ oven was the following: $50{ }^{\circ} \mathrm{C}$ (hold $1 \mathrm{~min}$ ), ramp to 110 ${ }^{\circ} \mathrm{C}$ at $6{ }^{\circ} \mathrm{C} / \mathrm{min}$, ramp to $180^{\circ} \mathrm{C}$ at $20^{\circ} \mathrm{C} / \mathrm{min}$ (hold $3 \mathrm{~min}$ ), and ramp to $220^{\circ} \mathrm{C}$ at $5{ }^{\circ} \mathrm{C} / \mathrm{min}$. The injector, the quadrupole, the source and the transfer line temperature were maintained at $240{ }^{\circ} \mathrm{C}, 150^{\circ} \mathrm{C}, 230^{\circ} \mathrm{C}$ and $200^{\circ} \mathrm{C}$, respectively. Electron ionization mass spectra in full-scan mode were recorded at $70 \mathrm{eV}$ electron energy in the range 31-350 amu (Rux et al 2019). Identification of volatile compounds was achieved by comparing mass spectra with the Wiley and Nist libraries (Wiley 7, NIST 05). The proportion of each compound was estimated dividing its mean area by the total area of the chromatogram and expressed as percentage. Blank experiments were carried out in two different modalities: blank of the fiber and blank of the empty vial. Controls were processed every 4 analyses of the experimental samples. All the analyses were performed in duplicate and the results expressed as mean value of three technical replicates \pm standard deviation.

\subsection{Statistical analysis}

The Tukey-Kramer's Honest Significant Difference (HSD) test (level of significance 0.05) was used to evaluate differences within samples by one-way analysis of variance (ANOVA). Tests were carried out using the software JMP Version 11.0.0 (SAS Institute Inc., Cary, NC).

Diversity indices (alpha) were calculated using the diversity function of the vegan package in R. Anosim and Adonis statistical test were used to find differences in microbial composition in R environment. Pairwise Wilcoxon test was used to determine significant differences in alpha diversity or OTU abundance. PICRUst tools (Langille et al., 2013) were used to predict the potential metabolic pathway of the sausages microbiota. Inferred KEGG Orthology (KO) gene tables was imported in the GAGE Bioconductor package to identify biological pathways overrepresented or underrepresented 
between the two batches. Spearman's correlations between OTUs and VOCs was performed by using the psyc package and visualized by the corrplot package of R. Multiple regression analyses were performed through SPSS v.26 to evaluate the associations between volatile compounds (dependent variable) and microbial taxa abundance.

\section{Results and Discussion}

\subsection{Physico-chemical characterization}

The results of the physico-chemical characterization of cacholeira blood sausages were reported in Table 1. Regarding $\mathrm{a}_{\mathrm{w}}$, the samples from batch 2 showed a significantly lower overall mean value than the samples from batch 1 (Table 1 ). When compared with the available data from the scientific literature, $\mathrm{a}_{\mathrm{w}}$ values found in cacholeira blood sausage were lower than those reported for Sanganel, a typical blood sausage from the Friuli Venezia Giulia Region (Italy), which attested at 0.96 (Iacumin et al., 2017). By contrast, they were almost overlapping with those detected in Paio Preto and Chouriço Preto, two fermented sausages containing Alentejano swine meat and blood, which attested at 0.80 and 0.84 , respectively (Laranjo et al., 2017).

No significant differences were seen between the overall $\mathrm{pH}$ means of the two analyzed batches (summer vs autumn) (Table 1). The detected $\mathrm{pH}$ values were in accordance with those already reported for other blood sausages, such as Paio Preto and Chouriço Preto, attesting at 5.2 and 5.4, respectively (Laranjo et al., 2017), whereas they notably differed from those detected in Sanganel, attesting at about 7 (Iacumin et al., 2017).

Regarding lactic acid determination, no significant differences were seen between the overall means of the two analyzed batches, with lactic acid content being significantly higher than that of acetic acid (Table 1). It is noteworthy that, in fermented sausages, both lactic and acetic acids are responsible for the definition of the sensory traits of the end product (Belleggia et al., 2020), with lactic acid being usually detected at a higher concentration than acetic acid, as main product of LAB metabolism (Milićević, Danilović, Džinić \& Savić, 2019).

Similarly to organic acids content, no significant differences were evidenced between the two analyzed batches for TTA overall mean values (Table 1).

The result of proximate analysis of the analyzed cacholeira blood sausages were reported in Supplementary Table 1.

\subsection{Viable counting}


The results of viable counts were reported in Table 1. Overall, an active microbial community mainly composed by lactic acid bacteria, coagulase negative cocci, enterococci and eumycetes was revealed.

Regarding presumptive lactobacilli grown on MRS medium, no significant differences were found between the overall means of the two analyzed batches (Table 1). Viable counts of this microbial group were in accordance with those reported for Morcela de Arroz, a cooked blood sausage from a further Portuguese Region (Monchique) (Pereira, Dionísio, Patarata \& Matos, 2015), but slightly lower than those reported for Paio Preto and Chouriço Preto, which were comprised between 6.7 and $8.2 \log \mathrm{cfu} / \mathrm{g}$ (Laranjo et al., 2017). The counts detected in cacholeira were also lower than those reported for Sanganel, which attested at about $8.5 \mathrm{log} \mathrm{cfu} / \mathrm{g}$ (Iacumin et al., 2017). It is noteworthy that, in the Iberian Peninsula, blood obtained from pig slaughtering is commonly used by the food industry for its nutritional value and functional properties (Dàvila, Saguer, Toldrà, Carretero \& Parés, 2006). Porcine blood, which is rich in heme iron and proteins of high nutritional and functional quality (Fontes, Gomide, Fontes, Ramos \& Ramos, 2010) can constitute a growth substrate for spoilage microorganisms and even foodborne pathogens. Interestingly, Dàvila et al. (2006) reported that, under refrigerated conditions, lactic acid bacteria are able to protect blood from spoilage. Moreover, Parés, Zamora, Saguer \& Carretero (2004) reported that the addition of glucose can enhance the antagonistic activity of lactic acid bacteria towards pathogens. Hence, it is likely that the combined occurrence of blood and sugar in the analysed cacholeira sausages might have increased the competitiveness of lactic acid bacteria.

As for coagulase negative cocci, no significant differences were seen between the overall means of the two batches (Table 1). In French, Spanish and Portuguese sausages coagulase negative cocci represent the second dominant bacterial group after lactic acid bacteria. The counts of coagulase negative cocci detected in the analyzed cacholeira samples were similar with those reported for Paio Preto (3.3 log cfu/g) and Chouriço Preto (4.0 log cfu/g) (Laranjo et al., 2017) and lower than those reported for Sanganel (6.0 log cfu/g) (Iacumin et al., 2017). As reported by Iacumin et al. (2017), in fermented sausages coagulase-negative cocci exert a lipolytic and proteolytic action, being also responsible for the final pigmentation of the meat batter.

Also for enterococci counts, no significant differences were seen between the overall means of the two analyzed batches (Table 1). Viable counts were in accordance with those reported by Iacumin et al. (2017) in the blood sausage Sanganel, but higher than those reported by Laranjo et al. (2017) in Paio Preto and Chouriço Preto. It is noteworthy that, in fermented sausages, enterococci can lead to the release of cadaverine and putrescine through decarboxylation of amino acids (Martín et al., 2006).

Pseudomonadaceae and Enterobacterales counts were $<1 \log \mathrm{cfu} / \mathrm{g}$ in all the analyzed samples, except for C7 where the latter microorganisms reached a mean count of $1.1 \pm 0.2 \log \mathrm{cfu} / \mathrm{g}$ (Table 1$)$. 
Regarding eumycetes, significantly higher overall mean counts were seen in the samples from the autumn production in respect with those manufactured in spring (Table 1). The counts found in the samples produced in autumn were in accordance with those previously detected in other blood containing sausages, such as Paio Preto, Chouriço Preto and Sanganel, which attested at 5.1, 4.6 and $5.0 \mathrm{log} \mathrm{cfu} / \mathrm{g}$, respectively (Laranjo et al., 2017; Iacumin et al., 2017). As previously elucidated, the surface microbiota of fermented sausages, including yeasts, can be affected by the environmental ripening conditions (Moretti et al., 2004) and especially by air physico-chemical parameters, such as temperature and relative humidity (Baldini et al., 2000). In fact, thermo-hygrometric conditions can considerably affect the velocity of evaporation and diffusion of water contained in sausages, thus leading to significant differences in the $\mathrm{NaCl} / \mathrm{H}_{2} \mathrm{O}$ ratio, which in turn is known to influence the multiplication of microorganisms (Baldini et al., 2000).

In fermented sausages, yeasts use lactic acid produced by lactic acid bacteria and allow a proper sausage drying by protecting it against fluctuations in humidity (Lücke, 2000). They can also contribute to flavor formation through the release of free fatty acids, peptides and free amino acids due to proteolysis and lipolysis (Flores, Corral, Cano-García, Salvador, \& Belloch, 2015). Moreover, molds (e.g. pro-technological Penicillium species) can contribute to flavor formation and protection of sausages against lipid oxidation (Magistà, Susca, Ferrara, Logrieco \& Perrone, 2017).

Regarding sulfite-reducing clostridia, counts $<1 \log \mathrm{cfu} / \mathrm{g}$ were detected in all the analyzed samples. As far as pathogens are concerned, L. monocytogenes or Salmonella spp. were never detected in the analyzed cacholera sausages, irrespective of the production season, thus evidencing the high quality of the raw materials and the application of adequate good hygiene practices.

\subsection{S rRNA gene amplicon target sequencing}

The total number of high-quality paired end sequences obtained from 16S rRNA gene sequencing reached 285,744 reads, with a mean value of 19,813 $\pm 4,557$ reads/sample and a mean sequence length of $460 \mathrm{bp}$. The rarefaction analysis and Good's coverage, expressed as a mean percentage (98\%), also indicated a satisfactory coverage. By comparing the alpha diversity index between the two productions, a variation of the number of OTUs according to the season was observed (the highest in autumn production, Figure 2, panel a, FDR $<0,05$ ).

The analyzed cacholeira blood sausages showed a simple bacterial composition dominated by Lactobacillus sakei, which attested at 90 and $89 \%$ of the bacterial species relative abundance in the summer (batch 1) and autumn production (batch 2), respectively (Figure 3, panel a).

The prevalence of $L$. sakei in the analyzed samples confirms the key role of this microorganism in the fermentation of cured meat products. So far $L$. sakei has been detected in other sausages from the Iberian Peninsula, such as Alheira, a 
further Portuguese traditional sausage (Albano, Henriques, Correia, Hogg \& Teixeira, 2008) and Chorizo, Salsichòn, Fuet and Androlla manufactured in Spain (Aquilanti et al., 2016). The notable adaptation of $L$. sakei to the meat environment is also suggested by of its previous detection in Italian, Belgian, French and Greek salami (Federici et al., 2014; Aquilanti et al., 2016; Cardinali et al., 2018; Janssens, Myter, De Vuyst \& Leroy, 2012; Aquilanti et al., 2007), irrespective of their ripening time. As evidenced by Ferrocino et al. (2018), in dry fermented sausages, carbohydrate metabolic pathways of L. sakei are responsible for the development of VOCs, such as acetate, acetoin, diacetyl, acetic acid and isobutyric acid that notably contribute to the definition of the typical aroma of these products. Moreover, L. sakei is able to utilize glucose, fructose and different hexoses as primary energy sources during the initial growth stage; hence, it is likely that sugar added to the analyzed cacholeira sausages might have selected for the massive growth of this microorganism. L. sakei produces lactate mainly deriving from the homolactic fermentation of hexoses via the glycolytic pathway, whereas acetate is produced through heterolactic fermentation of pentoses (Ferrocino et al., 2018). Moreover, as reported by Fadda et al. (1999), L. sakei exerts proteinase and aminopeptidase activities on proteins of sarcoplasmic and myofibrillar origin (Fadda et al., 1999), using free amino acids and even nucleotides as energy sources (Ferrocino et al., 2018).

Besides to L. sakei, minor components of the bacterial community were identified in the analyzed cacholera sausages, with a low relative abundance; these included Carnobacterium $(0.1$ and $1 \%$ of the bacterial species relative abundance in batch 1 and 2, respectively); Enterococcus and Kluyvera (0.2 and $1 \%$ in batch 1 and 2, respectively); Lactobacillus curvatus ( 0.3 and $0.2 \%$ in batch 1 and 2, respectively); Lactococcus garvieae ( 0.4 and $0.2 \%$ in batch 1 and 2, respectively); and Serratia (0.05 and 2\% in batch 1 and 2, respectively) (Figure 3, panel a). The principal component analysis showed a separation of the two batches based on the minor OTUs fraction (Supplementary Figure 1, anosim $=0.01$ ). In more detail, Lactobacillus curvatus and Lactococcus garvieae were associated with batch 1, whereas Carnobacterium, Enterococcus, Kluyvera, Serratia, Streptococcus and Vagococcus were associated with batch 2 (Supplementary Figure 2, FDR $<0.05)$.

\subsection{Mycobiota composition}

A total of $1,136,433$ clean reads were used, with a mean value of $81,549 \pm 34,397$ reads/sample and a mean sequence length of $392 \mathrm{bp}$. The rarefaction analysis and Good's coverage, expressed as a mean percentage (99\%), also indicated a satisfactory coverage. Regarding the alpha diversity, a higher number of OTUs and diversity was found in the summer production (batch 1) in respect with the autumn production (batch 2) (Figure 2, panel b, FDR < 0.05).

In particular, batch 1 was dominated by Starmerella apicola (31\% of the fungal species relative abundance), followed by D. hansenii (19\%), Candida tropicalis (15\%), Aspergillus (5\%) and Kurtzmaniella zeylanoides (4\%), whereas batch 2 
was dominated by Debaryomyces hansenii (99\%) (Figure 3, panel b). Even for mycobiota, a clear separation of the samples produced in summer (batch 1) and autumn (batch 2) was seen (Supplementary Figure 3, anosim $=0.01$ ), with batch 1 being characterized by the occurrence of Debaryomyces hansennii, Candida tropicalis, Kurtzmaniella zeylanoides, Saccharomyces cerevisiae, Kurtzmaniella santamariae, Aspergillus, Aspergillus niger, Yarrowia lipolytica, Brettanomyces bruxellensis and Pichia kluyveri (Supplementary Figure 4, FDR <0.05).

D. hansenii represents the yeast most frequently detected in fermented sausages. This species is able to hydrolyze pork muscle sarcoplasmic proteins, thus affecting the sensory traits of the product through the release of volatile compounds (Purriños et al., 2013; Santos et al., 2001). Furthermore, Cano-Garcia et al. (2014) highlighted that the presence of lipolytic activities in $D$. hansenii strains may exert an important effect on flavor development. The authors found that, in a meat model system, some strains of $D$. hansenii, with strong lipolytic activity, produced high amounts of ester compounds (ethyl esters and acetate esters) and low amounts of acetic acid. Moreover, Olesen \& Stahnke (2000) showed that the metabolic activity of $D$. hansenii increases the content of ammonia and reduces the content of lactic and acetic acid, with a subsequent raise in $\mathrm{pH}$ and a more palatable taste of the end product.

As far as the authors know, this is the first report of S. apicola (syn. Torulopsis apicola), previously known as Candida apicola, in fermented sausages, thus representing an advancement in the knowledge of the mycobiota associated with cured meat products. S. apicola is a highly osmotolerant ascomycete able to produce sophorolipids (biosurfactants), membrane fatty acids and enzymes (such as reductases and proteases) of biotechnological interest (Vega-Alvarado et al., 2015). So far, S. apicola has been isolated from fermented beverages, such as wine, Cachaça and Mescal, where it produced volatile compounds, thus suggesting a potential contribution of this yeast to the definition of cacholera sensory attributes.

Regarding the minor yeast components, C. tropicalis has previously been isolated from boiled sausages (Staib et al., 1980) and, more recently, from heat processed meat products (Dorn-In et al., 2013), thus likely explaining its detection in the analyzed cacholeira sausages subjected to blanching. Being able to colonize the human gastrointestinal tract (Egue, N'guessan, Aka-Gbezo, Bouatenin \& Koussemon-Camara, 2018) this yeast can be responsible for a fungal infection, known as candidiasis, hence in cacholera it might represent a health treat for the consumer that require further investigation.

Finally, K. zeylanoides (formerly known to as Candida zeylanoides) is a psychrotrophic yeast that has previously been found in "Nduja of Spilinga", a PGI spreadable Italian salami (Giarratana et al., 2014) and in the meat batter destined for the production of the Chorizo salami (Encinas, López-Díaz, García-López, Otero \& Moreno, 2000). Members of the genus Candida have also been detected in "salsiccia sotto sugna", a typical salami from the Lucania Region (southern Italy) (Gardini et al., 2001). 
If the results of viable counts are comparatively evaluated with those of the metagenomic approach, some hypotheses can be formulated to explain the differences seen in the range of yeast counts and species identified from sausages manufactured in summer and autumn, respectively. In fact, a significantly lower yeast load but higher yeast diversity was seen in batch 1 (summer production) in respect with batch 2 (autumn production). Differences were also seen in the core mycobiota of the two batches. Thus, for example, the incidence of $D$. hansenii was markedly lower in the samples from batch 2 as compared with batch 1 . An opposite but less pronounced trend was observed with S. apicola.

Differences (presumed) in meat composition, environmental conditions and process parameters appeared to influence the load and relative proportions of the yeast species identified in summer and autumn. Interestingly, seasonal variations in yeast species abundance have previously been reported in other fermented foods of animal origin (Viljoen, Khoury, \& Hattingh, 2003).

\subsection{SPME-GC-MS analysis of volatile components}

Seventy-two volatile compounds, belonging to various chemical classes, were identified through SPME-GC/MS (Table

2). The majority of these compounds belonged to seven main classes, being esters (16), phenols (13), terpenoids (10), acids (8), alcohols (7), ketones (7) and aldehydes (5). Lactones (2), furans (1), sulphur (1), nitrogen (1) and other compounds (1) were also identified.

It is noteworthy that many VOCs originate from the microbial metabolism and especially from carbohydrate esterase activity. Other VOCs derive from the smoking process or from the spices used for the preparation of meat-based products as highlighted by many authors (Nowicka et al., 2017; Sha et al., 2017; Škrlep et al., 2019). Numerous volatile components of cacholeira samples under study derived from lipid auto-oxidation and enzymatic degradation by the meat itself. It is well known that the compounds derived from lipid oxidation play an important role in the development of the typical aroma of fermented meat products during ripening or dry-curing stages (Domínguez et al., 2019; Toldrà \& Hui, 2014). As a general trend, from a qualitative point of view, the two batches showed a similar aroma profile. However, significant differences were seen in the abundance of some compounds, as a feasible consequence of presumed differences occurring in the raw materials and ingredients used (especially spices), microbiota composition and process parameters (e.g. temperature and length of fermentation; length of the smoking process, etc.) applied in the two artisan productions as well as of seasonal variations.

Among esters, ethyl esters, namely ethyl acetate, ethyl butanoate, ethyl hexanoate, ethyl lactate, ethyl octanoate, ethyl decanoate and ethyl isovalerate, were the most abundant. This class of compounds has previously been found in readyto-eat Chorizo sausages (Mateo \& Zumalacarregui, 1996). 
The higher proportion of ethyl acetate, isoamylacetate, ethyl pentanoate, ethyl hexanoate and ethyl-2-hydroxy-butanoate were found in sausages produced in summer season.

Esters are very fragrant compounds that substantially contribute to the highly appreciated fruity aroma notes of dry sausages. These compounds can originate from the esterification of alcohols and acids carried out by different microorganisms, including lactic acid bacteria, yeasts and molds (Flores et al., 2015). Even staphylococci are known to exhibit esterase activity; hence, they potentially contribute to the esterification of alcohols and acids occurring in sausages (Marco, Navarro \& Flores, 2008; Talon, Chastagnac, Vergnais, Montel \& Berdague, 1998).

In all the samples analyzed in this study numerous esters were detected, with some compounds (ethyl acetate, isoamylacetate, ethyl pentanoatre, ethyl hexanoate, and ethyl-e-hydroxy-butanoate) closely associated to Pichia kluyvery, Yarrowia lipolitica, Candida galli and Kurtzmaniella Santamaria being significantly more abundant in the sausages manufactured in summer.

Thirteen phenols were also identified, with most of them deriving from the smoke from burning of wood. Within this class, guaiacol, phenol, eugenol, 2-methoxy-4-methyl- and 2,6-dimethoxyphenol were the most prevalent; for many of these VOCs, a higher percentage was detected in the sausages from batch 1 (summer production) in respect with those from batch 2 (autumn production).

In addition, a considerable production of different alcohols was also detected in cacholeira, with ethyl alcohol and isoamyl alcohol being the most abundant, especially in the sausages from autumn production. By contrast, for 2-furanmethanol ( a minor alcohol compound probably associated to the smoking process), a higher percentage was detected in the samples from batch 1. Benzyl alcohol and benzene ethanol, two aroma-active alcohols associated with rose floral odor notes, were also detected in the sausages from both productions. The detection of high amounts of alcohols in cacholeira might be feasibly attributed to the activities of the microorganisms occurring in the meat batter. Indeed, different authors highlighted that microorganisms contribute to the generation of flavor compounds through the degradation of amino acids and fatty acids and hence to the release of aldehydes, alcohols or acids with aromatic traits (Ordoñez \& de La Hoz, 2007; Flores et al., 2015). Interestingly, D. hansenii, which neatly dominated in the sausages manufactured in autumn, was positively correlated with ethyl alcohol, whereas Kluyvera, again associated with the autumn production, was closely correlated with isoamyl alcohol.

Among aldehydes, 3-methylbutanal and 2-methylbutanal were the most representative; these compounds probably derived from amino acid catabolism and 5-methylfurfural, with the latter compound being a characteristic product of the Maillard reaction. The compound 3-methylbutanal is recognized as the most potent odorant in dry fermented sausages, together with 3-methyl-butanoic and butanoic acids, ethyl butanoate, acetic and others (Flores et al., 2015; Marco et al., 2008). 
Numerous ketones were also identified in cacholeira, with typical volatile substances of wood smoke (3-methyl-2cyclopenten-1-one, 2,3-dimethyl-2-cyclopenten-1-on, 2-hydroxy-3-methyl-2-cyclopenten-1-one and 2-methylcyclopentanone) being the most represented (Mateo \& Zumalacarregui, 1996). When the two batches were compared, a significantly higher percentage of these compounds $(\mathrm{p}<0.05)$ was found in the samples produced in summer.

By contrast, acetoin, found at the same level in both the productions, might derive from microbial carbohydrate metabolism.

Moreover, eight volatile acids were identified in cacholeira. Among these compounds, acetic acid was predominant in both the productions. Significant differences were seen between the two batches for propanoic and butanoic acid, with the highest percentages of these two compounds in the sausages from summer production.

Nine terpenoids were also detected, namely cymol (p-cymene), $\gamma$-terpinene, $\beta$-pinene, caryophyllene, $\alpha$-phellandrene, acedrene, limonene, $\alpha$-pinene, and $\alpha$-thujene; the occurrence of these compounds is likely associated with the use of spices. In more detail, $\mathrm{p}$-cymene, $\gamma$-terpinene, $\beta$-pinene and $\alpha$-pinene are the major constituent of ajowan (Trachyspermum ammi (L.) (Syn. Carum copticum Hiern) seeds (Nagalakshmi, Shankaracharya, Pura Naik \& Jagan Mohan Rao, 2000), whereas $\alpha$-thujene, $\alpha$-pinene, camphene, sabinene, $\beta$-pinene, $\alpha$-phellendren, limonene, $\gamma$-terpinene and p-cymene have previously been found in pepper (Kundayo et al., 1988; Belleggia et al., 2020). A significant variability was observed between the two productions for the content of some terpenes, such as caryophyllene, $\beta$-pinene, $\alpha$-pinene and $\alpha$-thujene. Such a variability might feasibly be ascribed to the occurrence of differences in the abundance of spices added in the two productions or even to differences in the chemical composition of the meat cuts, given the fact that these compounds are typically found in herbs grazed by livestock (Iacumin et al., 2017).

Finally, other minor compounds were also found, including: allylsulfide, a sulphur compound dominating in black garlic (Abe, Hori \& Myoda, 2020); gamma and butyrolactones, two lactones probably originating from lipid oxidation; and benzonitrile, a nitrogen compound.

\subsection{Correlation analysis}

The results of the inferred metagenome showed that batch 1 had the highest score for the following microbial pathways deposited in the KEGG database: glycolysis; fatty acid biosynthesis; alanine, aspartate and glutamate metabolism; valine, leucine and isoleucine degradation; starch and sucrose metabolism (data not shown).

By plotting the correlation between VOCs and microbiota composition (FDR $>0.05$ ), a few correlations were found. In more detail, L. curvatus, L. garviae and Kluyera were closely correlated with different VOCs of microbial origin (Figure $4)$. 
In particular, L. curvatus and L. garviae, associated with batch 1 (Supplementary Figure 2), were correlated with numerous compounds found at significantly higher levels in the sausages from summer production (Table 2). In detail, $L$. curvatus was closely correlated with $2-3$ octanedione $(\beta=0.88 ; 95 \% \mathrm{CI}=0.0830 .276 ; \mathrm{P}=0.004)$, isoamyl acetate $(\beta=0.80$; 95\%CI $=0.519$ 3.532; $\mathrm{P}=0.017)$, ethyl pentanoate $(\beta=0.947 ; 95 \% \mathrm{CI}=1.773$ 3.604; $\mathrm{P}=0.001)$, ethyl-2idrossibutanoate ( $\beta=0.840 ; 95 \% \mathrm{CI}=0.3391 .573 ; \mathrm{P}=0.009)$, acetic $(\beta=0.853 ; 95 \% \mathrm{CI}=12.578$ 51.983; $\mathrm{P}=0.007)$ and butanoic acids ( $\beta=0.820 ; 95 \% \mathrm{CI}=0.7704 .311 ; \mathrm{P}=0.013)$, whereas $L$. garviae with $2-3$ octanedione $(\beta=0.863 ; 95 \% \mathrm{CI}=0.0420 .160$; $\mathrm{P}=0.006)$.

Furthermore, Kluyvera, associated with batch 2 (Supplementary Figure 2), were closely correlated with isoamyl alcohol ( $\beta=0.842 ; 95 \% \mathrm{CI}=0.7393 .355 ; \mathrm{P}=0.009)$, found at significantly higher levels in the sausages from autumn production (batch 2).

Many of these latter microorganisms were closely correlated with 2,3-octanedione, butanoic and propanoic acids, as well as numerous esters, such as ethyl acetate, isoamyl acetate, ethyl pentanoate, ethyl exanoate and ethyl 2-idrossibutanoate, found at significantly higher levels in the sausage from summer production (Table 2). These results are in accordance with other authors (Tjener \& Stanhke, 2007) that suggested yeast, molds and LAB as potential contributors of ester compounds in the aroma profile definition of fermented meat products. Different authors showed that among the volatile compounds analyzed in dry sausages, ester compounds contribute to fruity aroma notes associated with high acceptance of traditional dry sausages (Flores et al.; 2015; Corral et al., 2014). On the other hand, numerous authors have found the presence of some of the aforementioned yeast species such as D. hansenii, C. zeylanoides and Y. lipolytica at various stages of ripening of fermented meat products, showing a significant effect on sausage sensory characteristics (Flores et al., 2015).

Finally, an influence of Y. lipolytica, B. bruxellensis and P. kluyveri on the final characteristics of the sausages manufactured in summer might be hypothesized, based on the analysis of VOCs. Similarly, other authors (Iucci et al., 2007; Patrignani et al., 2007) have reported that strains of $Y$. lipolitica could exert a positive effect on the lipolytic patterns, volatile profiles and sensory properties of dried fermented sausages. Also, the isolation of Pichia spp. in numerous sausages suggests that this yeast species may play an important role in the maturation process as well as in the development of sensory characteristics (Ozturk \& Sagdic, 2014; Cocolin et al., 2006).

\section{Conclusions}


Specialty meat products, like cacholeira, are unique and high-value products made in small quantities from high-quality ingredients according to local traditions, which are usually deeply rooted in the territories of origin. These foods represent a source of biodiversity that draws its origin from the craftsmanship of the production process and the use of unique raw materials (e.g. blood, in the case of the cacholeira sausage). Hence, the study of the microbial populations occurring in these products might be helpful for researchers to gain a deeper understanding of the interactions between microorganisms and meat substrates and for producers to enhance the overall quality of their productions.

The overall results collected in the present study allowed the bacterial and fungal communities of artisan cacholeira blood sausages to be disclosed for the very first time. If, on the one hand, a simple bacterial biota neatly dominated by $L$. sakei was highlighted, on the other hand, a more complex mycobiota was revealed. An impact of the production season (summer vs autumn) on the loads and diversity of eumycetes as well as on the amount of some VOCs was also suggested.

To the authors' knowledge, the present study represents the first characterization of cacholeira blood sausage with regards to its physico-chemical, microbiological and volatile traits to be used as baseline for future studies on microbial dynamics of such meat-based product. Further research on a more ample number of production batches sampled from different local artisan producers is needed to better understand the microbial dynamics and the evolution of VOCs during manufacturing and ripening of cacholeira blood sausage.

\section{Declaration of Competing Interest}

The authors declare that they have no known competing financial interests or personal relationships that could have appeared to influence the work reported in this paper.

\section{References}

Albano, H., Henriques, I., Correia, A., Hogg, T., \& Teixeira P. (2008). Characterization of microbial population of 'Alheira' (a traditional Portuguese fermented sausage) by PCR-DGGE and traditional cultural microbiological methods. Journal of Applied Microbiology, 105(6), 2187-2194.

Aquilanti, L., Garofalo, C., Osimani, A., \& Clementi, F. (2016). Ecology of lactic acid bacteria and coagulase negative cocci in fermented dry sausages manufactured in Italy and other Mediterranean countries: an overview. International Food Research Journal, 23, 429-445. 
Aquilanti, L., Santarelli, S., Silvestri, G., Osimani, A., Petruzzelli, A., \& Clementi, F. (2007). The microbial ecology of a typical Italian salami during its natural fermentation. International Journal of Food Microbiology, 120, 136145.

Baldini, P., Cantoni, E., Colla, F., Diaferia, C., Gabba, L., Spotti, E., Marchelli, R., Dossena, A., Virgili, E., Sforza, S., Tenca, P., Mangia, A., Jordano, R., Lopez, M. C., Medina, L., Coudurier, S., Oddou, S., \& Solignat, G. (2000). Dry sausages ripening: influence of thermohygrometric conditions on microbiological, chemical and physicochemical characteristics. Food Research International, 33, 161-170.

Belleggia, L., Milanović, V., Ferrocino, I., Cocolin, L., Haouet, M. N., Scuota, S., Maoloni, A., Garofalo, C., Cardinali, F., Aquilanti, L., Mozzon, M., Foligni, R., Pasquini, M., Trombetta, M. F., Clementi, F., \& Osimani, A. (2020). Is there any still undisclosed biodiversity in Ciauscolo salami? A new glance into the microbiota of an artisan production as revealed by high-throughput sequencing. Meat Science, 165, 108128.

Milićević, B., Danilović, B., Džinić, N., \& Savić, D. (2019). Changes in the organic acids content during the production of the petrovac sausage. Advanced technologies, 7(2), 41-45.

Cano-Garcia, L., Rivera-Jimenez, S., Belloch, C., \& Flores, M. (2014). Generation of aroma compounds in a fermented sausage meat model system by Debaryomyces hansenii strains. Food Chemistry, 151, 364-373.

Cardinali, F., Milanović, V., Osimani, A., Aquilanti, L., Taccari, M., Garofalo, C., Polverigiani, S., Clementi, F., Franciosi, E., Tuohy, K., Mercuri, M. L., Altissimi, M. S., \& Haouet, M. N. (2018). Microbial dynamics of model Fabriano-like fermented sausages as affected by starter cultures, nitrates and nitrites. International Journal of Food Microbiology, 278, 61-72.

Chapman, G. H. (1945). The significance of sodium chloride in studies of staphylococci. Journal of Bacteriology, 50, 201-203.

Cocolin, L., Urso, R., Rantsiou, K., Cantoni, C., \& Comi, G. (2006). Dynamics and characterization of yeasts during natural fermentation of Italian sausages. FEMS Yeast Research, 6, 692-701.

Corral, S., Salvador, A., \& Flores, M. (2014). Comparison of different extraction techniques for identification of key aroma compounds in traditional dry fermented sausages. Journal of the Science of Food and Agriculture, 95, 13501361.

Dàvila, E., Saguer, E., Toldrà, M., Carretero, C., \& Parés, D. (2006). Preservation of porcine blood quality by means of lactic acid bacteria. Meat Science, 73, 386-393.

Domínguez, R., Pateiro, M., Gagaoua, M., Barba, F.J., Zhang, W. \& Lorenzo, J.M. (2019). A Comprehensive review on lipid oxidation in meat and meat products. Antioxidants, 8, 429. 
Dorn-In, S., Hölzel, C. S., Janke, T., Schwaiger, K., Balsliemke, J., \& Bauer, J. (2013). PCR-SSCP-based reconstruction of the original fungal flora of heat-processed meat products. International Journal of Food Microbiology, 162(1), $71-81$

Egue, L. A. N., N'guessan, F. K., Aka-Gbezo, S., Bouatenin, J. K. M., \& Koussemon-Camara, M. (2018). Candida species in tchapalo and bangui, two traditional alcoholic beverages from Côte d'Ivoire. Fungal Biology, 122(5), $283-292$.

Encinas, J. P., López-Díaz, T. M., Garcia-López, M. L., Otero, A., \& Moreno, B. (2000). Yeast populations on Spanish fermented sausages. Meat Science, 54(3), 203-208.

Fadda, S., Sanz, Y., Vignolo, G., Aristoy, M. C., Oliver, G., \& Toldrà F. (1999). Hydrolysis of pork muscle sarcoplasmic proteins by Lactobacillus sakei and Lactobacillus curvatus. Applied and Environmental Microbiology, 65, 578584.

Federici, S., Ciarrocchi, F., Campana, R., Ciandrini, E., Blasi, G., \& Baffone, W. (2014). Identification and functional traits of lactic acid bacteria isolated from Ciauscolo salami produced in Central Italy. Meat Science, 98(4), 575584.

Ferrocino, I., Bellio, A., Giordano, M., Macori, G., Romano, A., Rantsiou, K., Decastelli, L., \& Cocolin, L. (2018). Shotgun Metagenomics and Volatilome Profile of the Microbiota of Fermented Sausages. Applied and Environmental Microbiology, 84(3), e02120-17.

Flores, M., Corral, S., Cano-García, L., Salvador, A., \& Belloch, C. (2015). Yeast strains as potential aroma enhancers in dry fermented sausages. International Journal of Food Microbiology, 212, 16-24.

Fontes, P. R., Gomide, L. A. M., Fontes, E. A. F., Ramos, E. M., \& Ramos, A. L. S. (2010). Composition and color stability of carbon monoxide treated dried porcine blood. Meat Science, 85, 472-480.

Gardini, F., Suzzi, G., Lombardi, A., Galgano, F., Crudele, M. A., Andrighetto, C., Schirone, M., \& Tofalo, R. (2001). A survey of yeasts in traditional sausages of southern Italy. FEMS Yeast Research, 1, 161-167.

Giarratana, F., Muscolino, D., Beninati, C., Giuffrida, A., Ziino, G., \& Panebianco, A. (2014). Characterization of yeasts isolated from 'Nduja of Spilinga. Italian Journal of Food Safety, 3, 78-80.

Haouet, M. N., Altissimi, M. S., Mercuri, M. L., Baldassarri, C., Osimani, A., Clementi, F., \& Ortenzi, R. (2017). Evaluation of the safety of Milano-type dry fermented sausages produced by a fast drying technology. Italian Journal of Food Science, 29, 1-9.

Iacumin, L., Manzano, M., Stella, S., \& Comi, G. (2017). Fate of the microbial population and the physico-chemical parameters of "Sanganel" a typical blood sausages of the Friuli, a north-east region of Italy. Food Microbiology, $63,84-91$.

Iucci, I., Patrignani, F., Belletti, N., Ndagijimana, M., Guerzoni, E., Gardini, F., \& Lanciotti, R. (2007). Role of surface- 
inoculated Debaryomyces hansenii and Yarrowia lipolytica strains in dry fermented sausages manufacture. Part 2: Evaluation of their effects on sensory quality and biogenic amine content, Meat Science, 75, 669-675.

Luo, J., Yan, W., Nasiru, M.M., Zhuang, H., Zhou, G. \& Zhang, J. (2019) Evaluation of physicochemical properties and volatile compounds of Chinese dried pork loin curing with plasma-treated water brine. Scientific Reports, 9, 13793.

Janssens, M., Myter, N., De Vuyst, L., \& Leroy, F. (2012). Species diversity and metabolic impact of the microbiota are low in spontaneously acidified Belgian sausages with an added starter culture of Staphylococcus carnosus. Food Microbiology, 29, 167-177.

Abe, K., Hori, Y., \& Myoda, T. (2020). Volatile compounds of fresh and processed garlic. Experimental and Therapeutic Medicine, 19, 1585-1593.

Klindworth, A., Pruesse, E., Schweer, T., Peplies, J., Quast, C., Horn, M., \& Glöckner, F. O. (2013). Evaluation of general 16S ribosomal RNA gene PCR primers for classical and next-generation sequencing-based diversity studies. Nucleic Acids Research, 41, 1-11.

Kundayo, O., Laakso, I., Adegbola, R. M., Oguntimein, B., Sofowora, A., \& Hiltunen, R. (1988). Essential oil constituents of Ashanti pepper (Piper guineese) fruits (Berries). Journal of Agriculture and Food Chemistry, 36, 880-882.

Langille, M. G. I., Zaneveld, J., Caporaso, J. G., McDonald, D., Knights, D., Reyes, J. A., Clemente, J. C., Burkepile, D. E., Vega Thurber, R. L., Knight, R., Beiko, R. G., \& Huttenhower, C. (2013). Predictive functional profiling of microbial communities using 16S rRNA marker gene sequences. Nature Biotechnology, 31, 814-821.

Laranjo, M., Gomes, A., Agulheiro-Santos, A. C., Potes, M. E., João Cabrita, M., Garcia, R., Rocha, J. M., Roseiro, L. C., Fernandes, M. J., João Fraqueza, M., \& Elias, M. (2017). Impact of salt reduction on biogenic amines, fatty acids, microbiota, texture and sensory profile in traditional blood dry-cured sausages. Food Chemistry, 218, 129136.

Leroy, F., Geyzen, A., Janssens, M., De Vuyst, L., \& Scholliers, P. (2013). Meat fermentation at the crossroads of innovation and tradition: A historical outlook. Trends in Food Science \& Technology, 31, 2, 130-137.

Lücke, F. K., (2000). Utilization of microbes to process and preserve meats. Meat Science, 56, 105-115.

Magistà, D., Susca, A., Ferrara, M., Logrieco, A. F., \& Perrone, G. (2017). Penicillium species: crossroad between quality and safety of cured meat production. Current Opinion in Food Science, 17, 36-40.

Marco, A., Navarro, J. L., \& Flores, M. (2008). The sensory quality of dry fermented sausages as affected by fermentation stage and curing agents. European Food Research and Technology, 226, 449-458.

Marcos, C., Viegas, C., de Almeida, A. M., Guerra, M. M. (2016). Portuguese traditional sausages: different types, nutritional composition, and novel trends. Journal of Ethnic Foods, 3, 51-60. 
Martín, B., Garriga, M., Hugas, M., Bover-Cid, S., Veciana-Nogués, M. T., \& Aymerich, T. (2006). Molecular, technological and safety characterization of Gram-positive catalase-positive cocci from slightly fermented sausages. International Journal of Food Microbiology, 107(2), 148-158.

Mateo J., \& Zumalacarregui, J. M. (1996). Volatile compounds in chorizo and their changes during ripening. Meat Science, 44, 255-273.

Moretti, V. M., Madonia, G., Diaferia, C., Mentasti, T., Paleari, M. A., Panseri, S., Pirone, G., \& Gandini, G. (2004). Chemical and microbiological parameters and sensory attributes of a typical Sicilian salami ripened in different conditions. Meat Science, 66(4), 845-854.

Mota-Gutierrez, J., Botta, C., Ferrocino, I., Giordano, M., Bertolino, M., Dolci, P., \& Cocolin, L. (2018). Dynamics and Biodiversity of Bacterial and Yeast Communities during Fermentation of Cocoa Beans. Applied and environmental microbiology, 84(19), e01164-18.

Nagalakshmi, S., Shankaracharya, N. B., Pura Naik, L., Jagan Mohan Rao, L. (2000). Studies on Chemical and Technological Aspects of Ajowan (Trachyspermum ammi (L.) Syn. Carum copticum Hiern) Seeds. Journal of Food Science and Technology, 37, 277-281.

Nowicka, K., Jaworska, D., Przybylski, W., Górska, E., Tambor, K., \& Półtorak, A. (2017). Determinants of the sensory quality of Półgęsek in relation to volatile compounds and chemical composition. Polish Journal of Food Nutrition Sciences, 67, 283-292.

Olesen, P. T., \& Stahnke, L. H. (2000). The influence of Debaryomyces hansenii and Candida utilis on the aroma formation in garlic spiced fermented sausages and model minces. Meat Science, 56, 357-368.

Ordoñez, J. A., \& de la Hoz, L. (2007). Mediterranean Products. In F. Toldrá, Y. H., Hui, I., Astiasarán, W., Nip, J. G., Sebranek, E. F., Silveira, L. H., Stahnke, R., Talon (Eds.), Hand-book of Fermented Meat and Poultry (pp. 333348). Iowa: Blackwell Publishing.

Ozturk, I., \& O. Sagdic. (2014). Biodiversity of yeast mycobiota in "sucuk," a traditional Turkish fermented dry sausage: Phenotypic and genotypic identification, functional and technological properties. Journal of Food Science, 79, 2315-2322.

Parés, D., Zamora, L., Saguer, E., \& Carretero, C. (2004). Acid lactic bacteria as biopreservative cultures in porcine blood for human consumption. FoodInfo Online Features. Available online: http://www.foodsciencecentral.com

Patrignani, F., Iucci, L., Vallicelli, M., Guerzoni, M. E., Gardini, F., \& Lanciotti, R. (2007). Role of surface-inoculated Debaryomyces hansenii and Yarrowia lipolytica strains in dried fermented sausage manufacture. Part 1: Evaluation of their effects on microbial evolution, lipolytic and proteolytic patterns. Meat Science, 75, 676-686. 
Pereira, J. A., Dionísio, L., Patarata, L., \& Matos, T. J. S. (2015). Effect of packaging technology on microbiological and sensory quality of a cooked blood sausage, Morcela de Arroz, from Monchique region of Portugal. Meat Science, $101,33-41$.

Petruzzelli, A., Foglini, M., Vetrano, V., Paolini, F., Orazietti, N., Ambrosini, B., Osimani, A., Clementi, F., Tavoletti, S., \& Tonucci, F. (2014). The occurrence of thermotolerant Campylobacter spp. in raw meat intended for public catering. Public Health, 128, 388-390.

Petruzzelli, A., Osimani, A., Pasquini, M., Clementi, F., Vetrano, V., Paolini, F., Foglini, M., Micci, E., Paoloni, A., \& Tonucci, F. (2016). Trends in the microbial contamination of bovine, ovine and swine carcasses in three smallscale abattoirs in Central Italy: a four-year monitoring. Meat Science, 111, 53-59.

Purriños, L., Carballo, J., \& Lorenzo, J.M. (2013). The influence of Debaryomyces hansenii, Candida deformans and Candida zeylanoides on the aroma formation of dry-cured "lacón”. Meat Science, 93, 344-350.

Santos, N.N., Santos-Mendonça, R.C., Sanz, Y., Bolumar, T., Aristoy, M.C., \& Toldrá, F. (2001). Hydrolysis of pork muscle sarcoplasmic proteins by Debaryomyces hansenii. International Journal Food Microbiology, 68, 199-206.

Sha, K., Zhang, Z., Sun, B., Li, H., Song, H., Lang, Y., Lei, Y., Li, H., \& Zhang, Y. (2017). Investigation of physicochemical and textural characteristics and volatile compounds of Kazakh dry-cured beef. Food Science and Technology Research, 23, 375-383.

Škrlep, M., Čandek-Potokar, M., Batorek-Lukač, N., \& Tomažin, U.M. (2019). Aromatic profile, physicochemical and sensory traits of dry-fermented sausages produced without nitrites using pork from Krškopolje pig reared in organic and conventional husbandry. Animals, 9, 55.

Staib, F., Mishra, S. K., Tompak, B., Grosse, G., Abel, T., Blisse, A., Folkens, U., \& Fröhlich, B. (1980). Pathogenic yeast-like fungi in meat products. Zentralblatt Bakteriologie, 248(3), 422-429.

Talon, R., Chastagnac, C., Vergnais, L., Montel, M. C., \& Berdague, J. L. (1998). Production of esters by Staphylococci. International Journal of Food Microbiology, 45, 143-150.

Tjener, K., \& Stanhke, L.H. (2007). Flavor. In: Toldrá, F. (Ed.), Handbook of Fermented Meat and Poultry. Blackwell Publishing, Iowa, USA, pp. 503-512.

Toldrà, F., \& Hui, Y.H. (2014). Dry-fermented sausages and ripened meats: An overview. In: Handbook of Fermented Meat and Poultry Book Editor(s): Fidel Toldrá ,Y. H. Hui , Iciar Astiasarán, Joseph G. Sebranek, Règine Talon ( $2^{\text {nd }}$ edition).

Tremonte, P., Sorrentino, E., Succi, E., Reale, A., Maiorano, G., \& Coppola, R. (2005). Shelf Life of Fresh Sausages Stored under Modified Atmospheres. Journal of Food Protection, 68, 2686-2692. 
Vega-Alvarado, L., Gómez-Angulo, J., Escalante-García, Z., Grande, R., Gschaedler-Mathis, A., Amaya-Delgado, L., Sanchez-Flores, A., \& Arrizon, J. (2015). High-Quality Draft Genome Sequence of Candida apicola NRRL Y50540. Genome Announcements, 3(3), pii:e00437-15.

Viljoen, B.C., Khoury, A.R., \& Hattingh, A. (2003). Seasonal diversity of yeasts associated with white-surface mouldripened cheeses. Food Research International, 36, 275-283. 


\section{FIGURE CAPTIONS}

Figure 1. Slice of ready-to-eat cacholeira blood sausage

Figure 2. Boxplots to describe $\alpha$-diversity measures of bacteria in batch 1 (red bars) and batch 2 (blue bars). Individual points represent the richness estimate and the theoretical standard error range, respectively (panel a). Boxplots to describe $\alpha$-diversity measures of mycobiota in batch 1 (yellow bars) and batch 2 (green bars). Individual points represent the richness estimate and the theoretical standard error range, respectively (panel b).

Figure 3. Bacterial composition detected by sequencing. Only OTUs with an incidence above $0.2 \%$ in at least two samples are shown (panel a). Mycobiota composition detected by sequencing. Only OTUs with an incidence above $0.2 \%$ in at least two samples are shown (panel b).

Figure 4. Correlation between the abundance of VOCs (\%) and OTUs that occurred at $0.2 \%$ in at least 2 samples. The color of the scale bar denotes the nature of the correlation, with 1 indicating a positive correlation (purple) and -1 indicating a negative correlation (yellow). Only significant correlations (FDR 0.05) are shown. 


\section{Credit author statement}

Luca Belleggia: Conceptualization, Formal analysis. Ilario Ferrocino: Formal analysis. Anna Reale: Writing - Review \& Editing. Floriana Boscaino: Formal analysis. Tiziana Di Renzo: Formal analysis. Maria Rita Corvaglia: Formal analysis. Luca Cocolin: Writing original draft. Vesna Milanović: Formal analysis. Federica Cardinali: Formal analysis. Cristiana Garofalo: Formal analysis. Francesca Clementi: Writing original draft. Lucia Aquilanti: Writing original draft. Andrea Osimani: Conceptualization, Writing - Review \& Editing, Supervision, Resources. 
Fig. 1

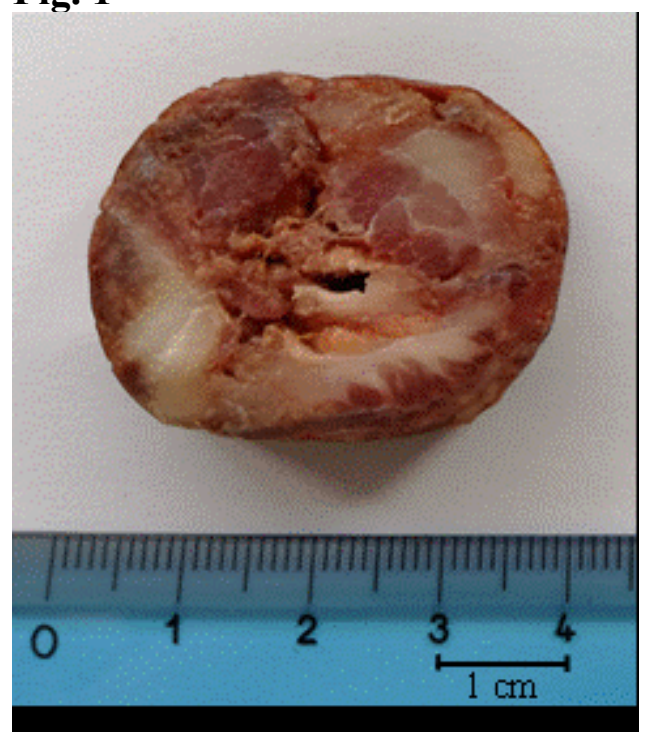

Fig. 2

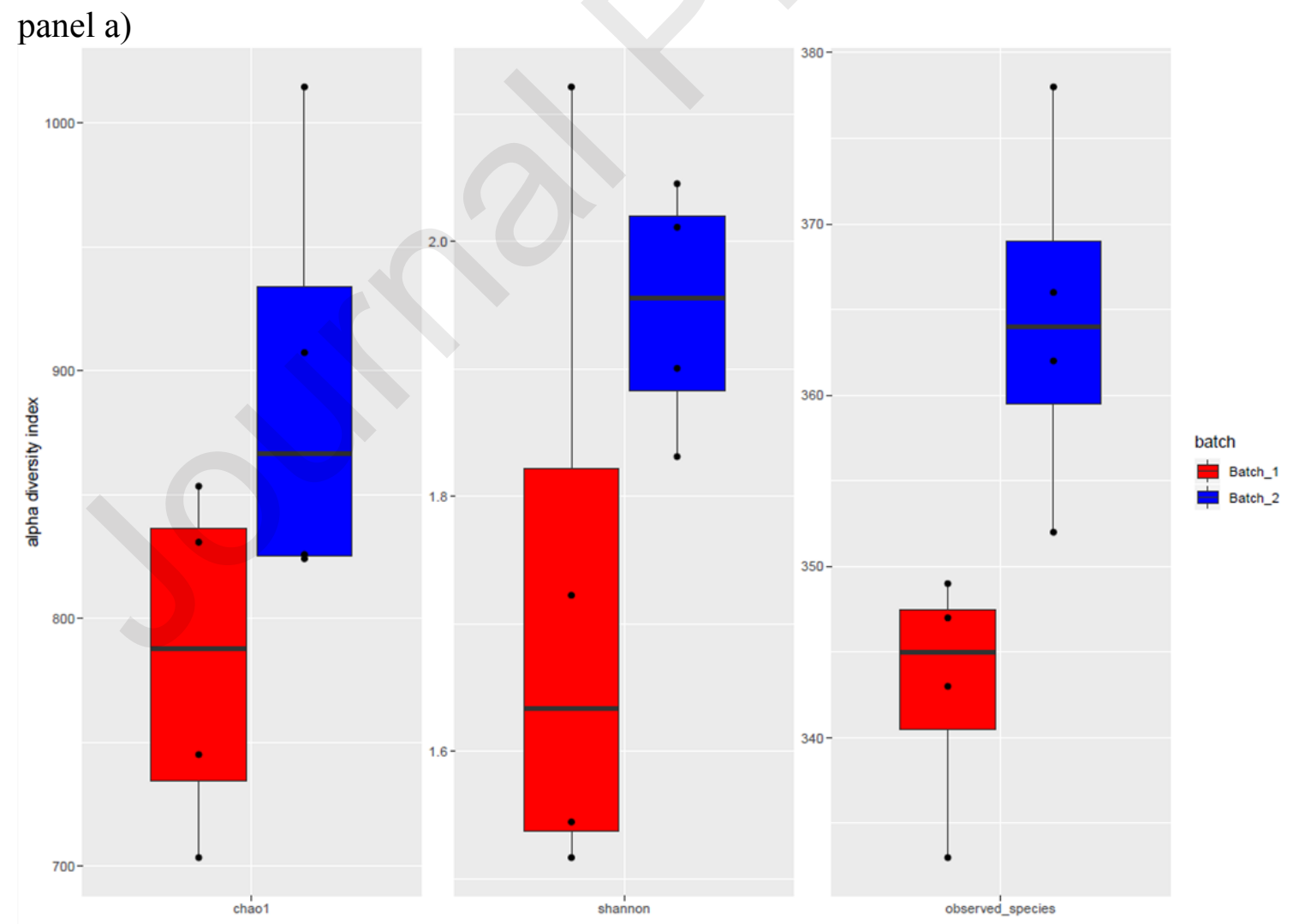

panel b) 


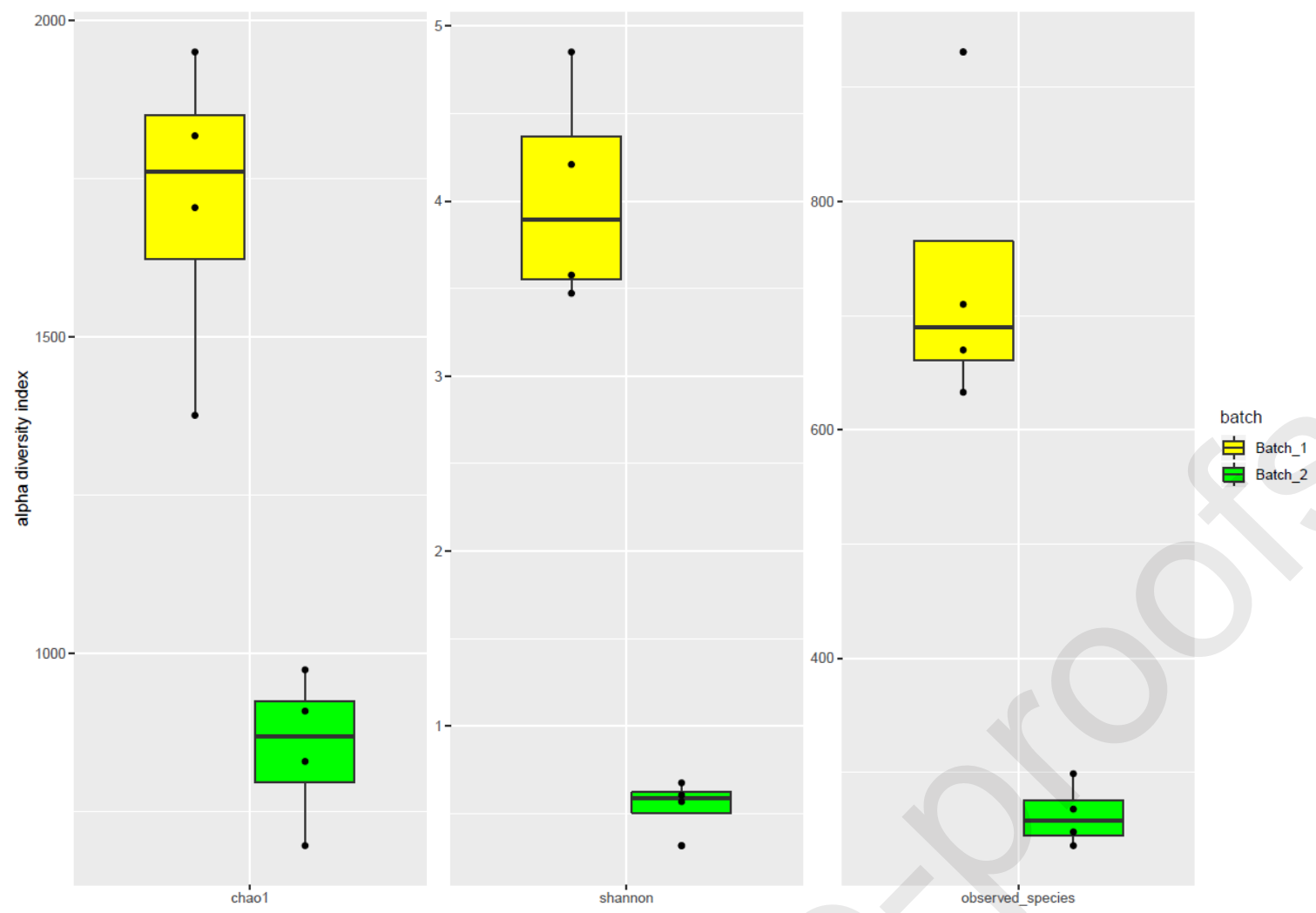


Fig. 3

panel a)

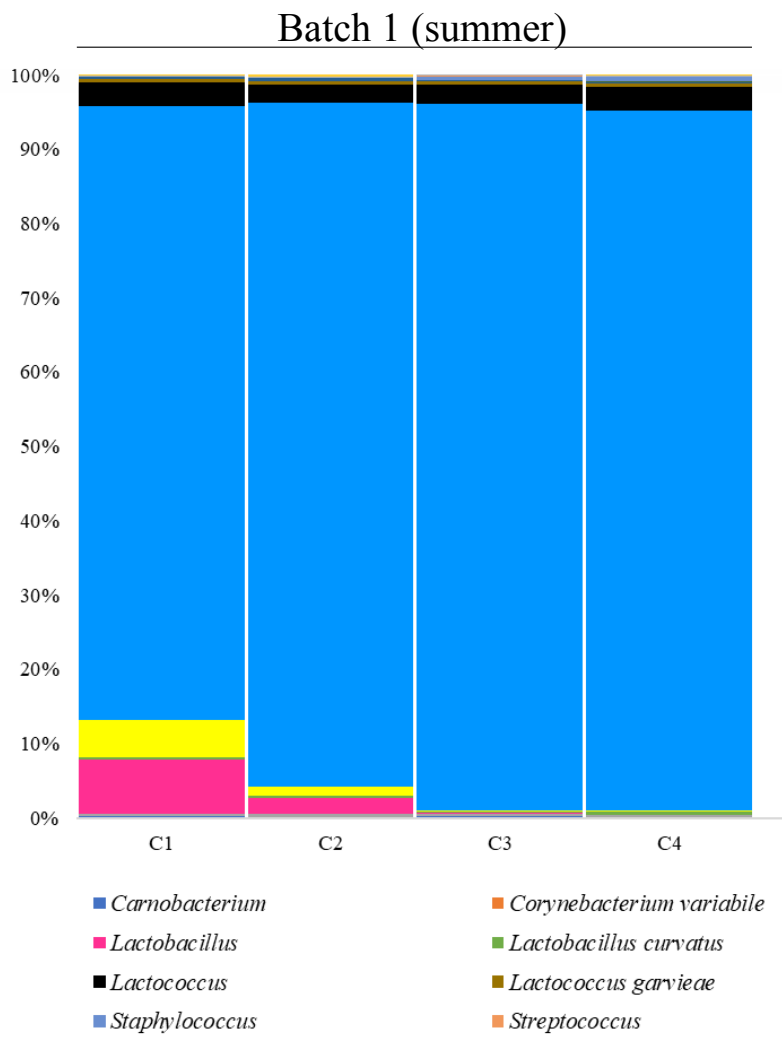

panel b)

Batch 1 (summer)

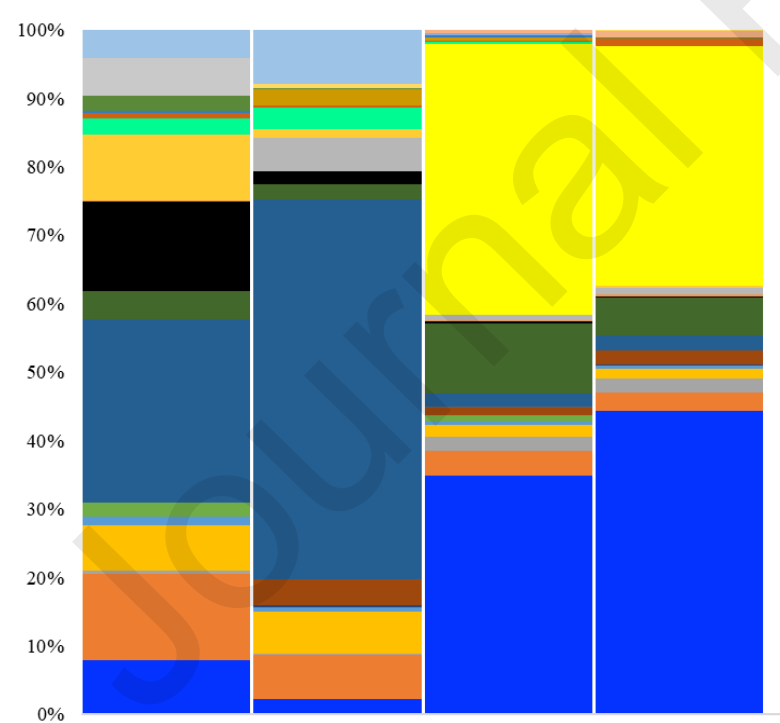

C1

C2

C3

$\mathrm{C} 4$

- Debaryomyces hansenii

- Kurtzmaniella santamariae

- Wickerhamomyces subpelliculosa

- Aspergillus niger

- Starmerella apicola

- Tausonia pullulans

- Starmerella sorbosivorans

$\llbracket$ Trichosporon asahii
- Kurtzmaniella zevlanoides

- Penicillium roqueforti

- Zygosaccharomyces pseudorouxii

- Debaryomyces suglobosus

- Wickerhamomyces anomalus

- Aspergillus fumigatus

- Clavispora lusitaniae
Batch 2 (autumn)

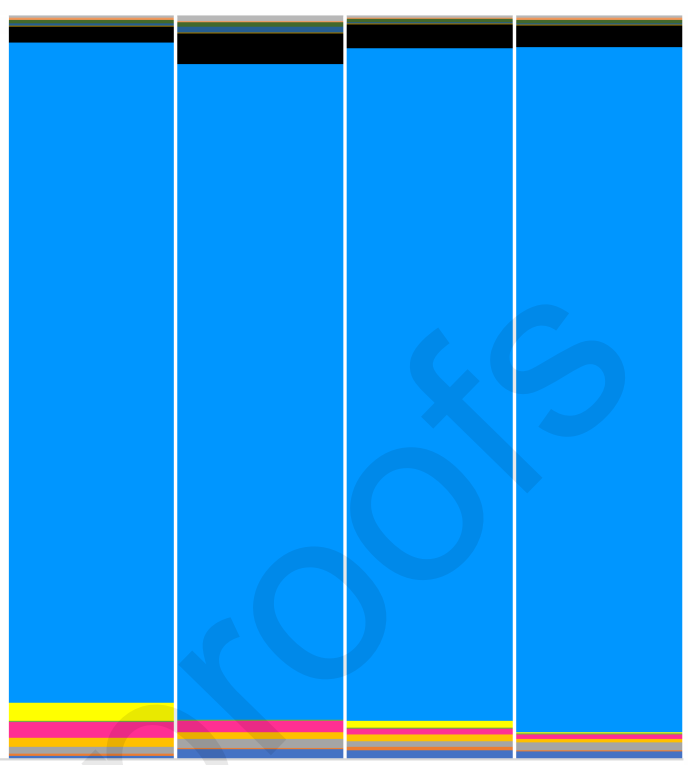

C7

C8

- Kluyvera

- Lactobacillus sakei

- Serratia

Weissella paramesenteroies
- Leuconostoc

Vagococcus
Batch 2 (autumn)

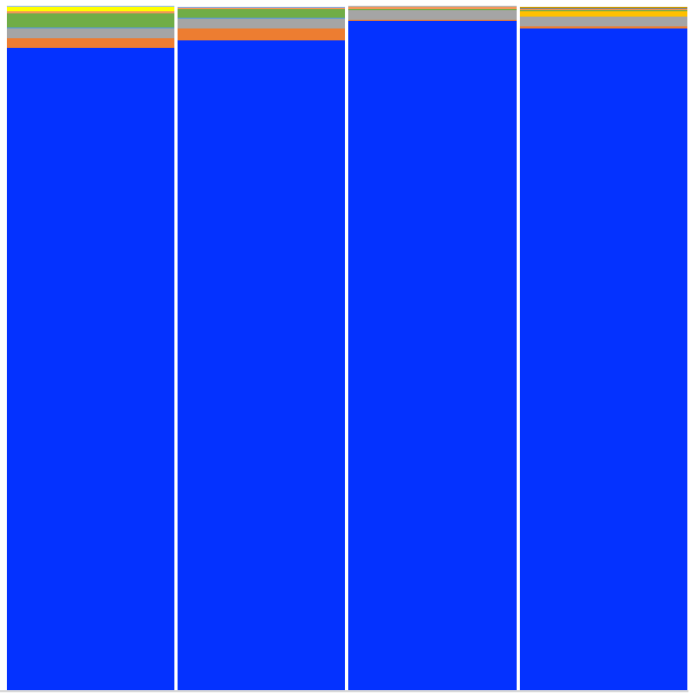

C5

C7

C8
Debaryomyces

- Zygosaccharomyces rouxi

Candida tropicalis

- Yarrowia divulgata

- Brettanomyces bruxellensis

- Penicillium

Candida boidinii
Saccharomyces cerevisiae

- Yarrowia deformans

-Aspergillus

Yarrowia lipolytica

- Pichia khyveri

- Candida galli

- Cystobasidium slooffiae 
Fig. 4

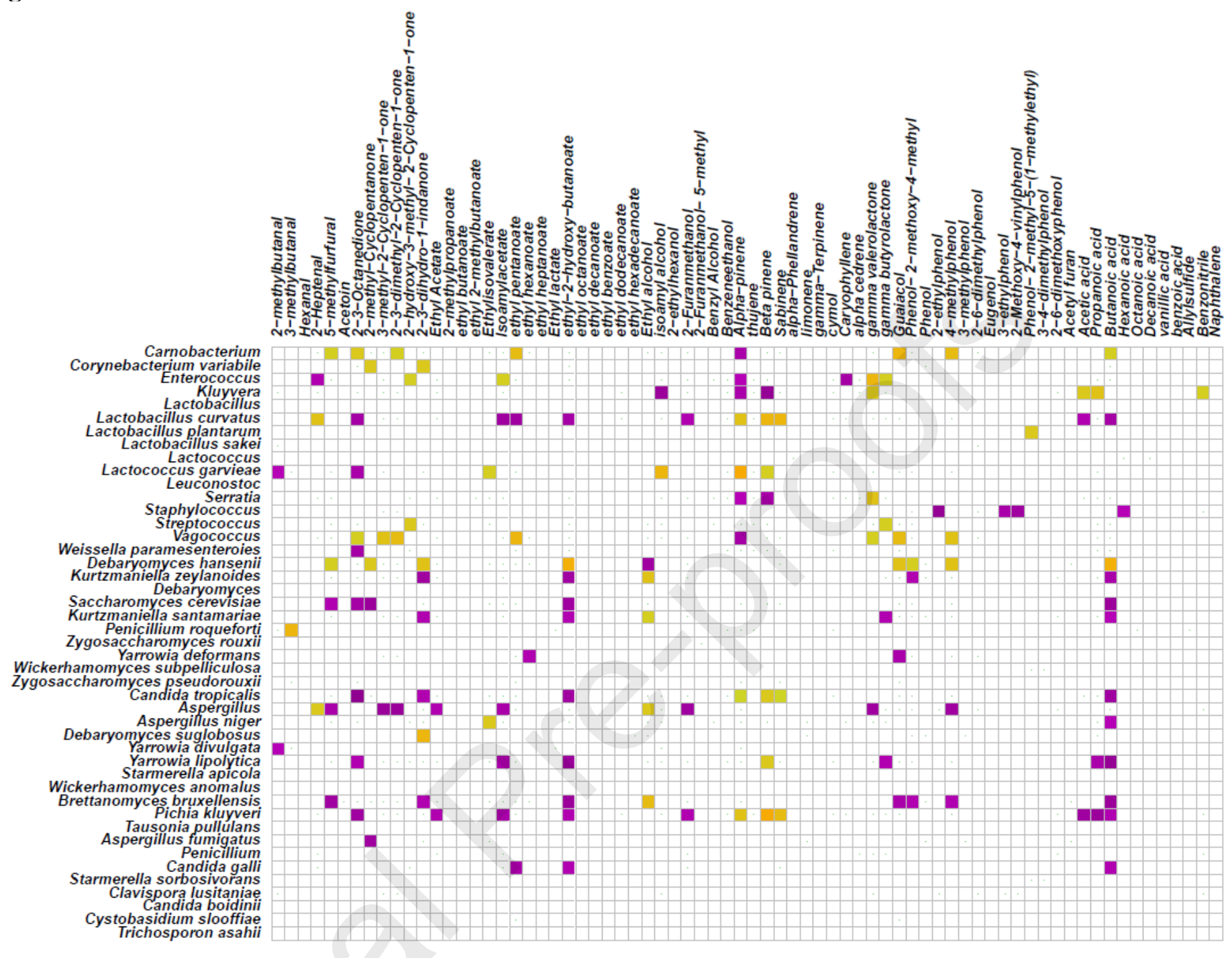




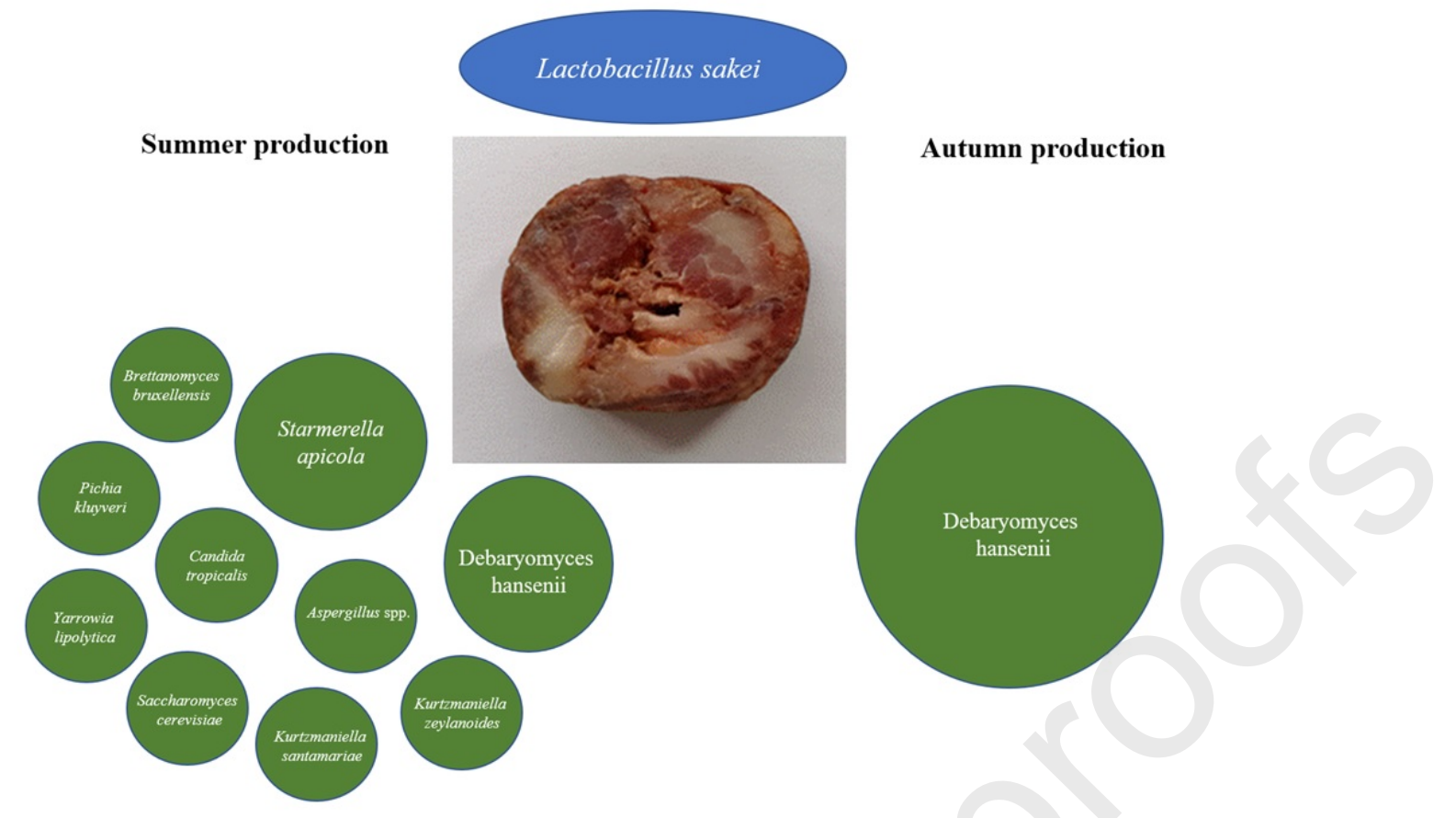


Table 1. Physico-chemical parameters and viable counts of the cacholeira blood sausage analyzed samples.

\begin{tabular}{|c|c|c|c|c|c|c|c|c|c|c|}
\hline & \multicolumn{5}{|c|}{ Batch 1 (summer) } & \multicolumn{5}{|c|}{ Batch 2 (autumn) } \\
\hline & $\mathrm{C} 1$ & $\mathrm{C} 2$ & $\mathrm{C} 3$ & $\mathrm{C} 4$ & $\begin{array}{l}\text { Overall } \\
\text { mean }\end{array}$ & C5 & C6 & $\mathrm{C} 7$ & $\mathrm{C} 8$ & $\begin{array}{l}\text { Overall } \\
\text { mean }\end{array}$ \\
\hline \multicolumn{11}{|l|}{$\begin{array}{l}\text { Physico-chemical } \\
\text { parameters }\end{array}$} \\
\hline \multirow[t]{2}{*}{$\mathrm{pH}$} & \multicolumn{5}{|c|}{$5.11 \pm 0.05 .23 \pm 0.05 .30 \pm 0.05 .34 \pm 0.05 .24 \pm 0$} & \multicolumn{5}{|c|}{$5.07 \pm 0.05 .07 \pm 0.05 .12 \pm 0.05 .21 \pm 0.05 .12 \pm 0}$. \\
\hline & 2 & 3 & 1 & 0 & $10^{\mathrm{a}}$ & 3 & 3 & 2 & 1 & $06^{\mathrm{a}}$ \\
\hline \multirow[t]{2}{*}{$a_{w}$} & \multicolumn{5}{|c|}{$0.820 \pm 0.0 .808 \pm 0.0 .811 \pm 0.0 .807 \pm 0.0 .811 \pm 0$} & \multicolumn{5}{|c|}{$0.916 \pm 0.0 .918 \pm 0.0 .920 \pm 0.0 .915 \pm 0.0 .917 \pm 0$} \\
\hline & 001 & 003 & 001 & 003 & $.006^{\mathrm{b}}$ & 001 & 001 & 003 & 001 & $.002^{\mathrm{a}}$ \\
\hline TTA (mL of & $16.55 \pm 0$ & $.21 .15 \pm 1$ & $23.45 \pm 2$ & $18.00 \pm 0$ & $19.8 \pm 3$ & $15.30 \pm 1$ & $.12 .90 \pm 0$ & $16.40 \pm 0$ & $15.10 \pm 0$ & $14.9 \pm 1$ \\
\hline $0.1 \mathrm{~N} \mathrm{NaOH})$ & 92 & 77 & 19 & 99 & $1^{\mathrm{a}}$ & 70 & 85 & 85 & 42 & $6^{b}$ \\
\hline Lactic acid & $1.152 \pm 0$ & $.1 .080 \pm 0$. & $1.078 \pm 0$ & $0.570 \pm 0$ & $0.970 \pm 0$ & $0.908 \pm 0$ & $0.894 \pm 0$. & $0.934 \pm 0$ & $1.139 \pm 0$ & $0.969 \pm 0$ \\
\hline$(g / 100 g)$ & 007 & 023 & 068 & 400 & $.293^{\mathrm{a}}$ & 072 & 332 & 102 & 151 & $.180^{\mathrm{a}}$ \\
\hline Acetic acid & $0.028 \pm 0$ & $.0 .025 \pm 0$ & $0.035 \pm 0$ & $0.036 \pm 0$ & $0.031 \pm 0$ & $0.031 \pm 0$ & $0.003 \pm 0$. & $0.008 \pm 0$ & $0.043 \pm 0$ & $0.021 \pm 0$ \\
\hline$(\mathrm{g} / 100 \mathrm{~g})$ & 008 & 004 & 008 & 003 & $.007^{\mathrm{a}}$ & 018 & 001 & 000 & 015 & $.020^{\mathrm{a}}$ \\
\hline \multicolumn{11}{|l|}{$\begin{array}{l}\text { Viable counts } \\
(\log \mathrm{cfu} / \mathrm{g})\end{array}$} \\
\hline \multirow{2}{*}{$\begin{array}{l}\text { Presumptive } \\
\text { lactobacilli } \\
\text { Enterococci }\end{array}$} & $4.9 \pm 0.1$ & $6.1 \pm 0.1$ & $5.2 \pm 0.1$ & $4.7 \pm 0.1$ & $\begin{array}{l}5.2 \pm 0.6 \\
\mathrm{a}\end{array}$ & $7.0 \pm 0.1$ & $6.2 \pm 0.0$ & $6.2 \pm 0.1$ & $5.7 \pm 0.1$ & $\begin{array}{l}6.3 \pm 0.5 \\
\mathrm{a}\end{array}$ \\
\hline & $4.1 \pm 0.0$ & $4.9 \pm 0.1$ & $3.2 \pm 0.1$ & $3.5 \pm 0.2$ & $\begin{array}{l}3.9 \pm 0.7 \\
\text { a }\end{array}$ & $4.0 \pm 0.1$ & $3.6 \pm 0.1$ & $3.7 \pm 0.1$ & $3.7 \pm 0.1$ & $\begin{array}{l}3.7 \pm 0.2 \\
\text { a }\end{array}$ \\
\hline $\begin{array}{l}\text { Coagulase } \\
\text { negative cocci }\end{array}$ & $3.3 \pm 0.0$ & $3.2 \pm 0.1$ & $5.2 \pm 0.1$ & $5.2 \pm 0.1$ & $\begin{array}{l}4.2 \pm 1.1 \\
\text { a }\end{array}$ & $3.1 \pm 0.2$ & $3.6 \pm 0.1$ & $3.3 \pm 0.2$ & $3.1 \pm 0.1$ & $\begin{array}{l}3.3 \pm 0.3 \\
\mathrm{a}\end{array}$ \\
\hline $\begin{array}{l}\text { Pseudomonadace } \\
\text { ae }\end{array}$ & $e<1$ & $<1$ & $<1$ & $<1$ & $\begin{array}{l}0.0 \pm 0.0 \\
\mathrm{a}\end{array}$ & $<1$ & $<1$ & & $<1$ & $\begin{array}{l}0.0 \pm 0.0 \\
\mathrm{a}\end{array}$ \\
\hline Enterobacterales & $<1$ & $<1$ & $<1$ & $<1$ & $\begin{array}{l}0.0 \pm 0.0 \\
\text { a }\end{array}$ & & $<1$ & $1.1 \pm 0.2$ & $<1$ & $\begin{array}{l}0.3 \pm 0.5 \\
\text { a }\end{array}$ \\
\hline $\begin{array}{l}\text { Sulfite-reducing } \\
\text { clostridia }\end{array}$ & $<1$ & $<1$ & $<1$ & $<1$ & $\begin{array}{l}0.0 \pm 0.0 \\
\text { a }\end{array}$ & $<1$ & $<1$ & $<1$ & $<1$ & $\begin{array}{l}0.0 \pm 0.0 \\
\mathrm{a}\end{array}$ \\
\hline Eumycetes & $<1$ & $<1$ & $1.5 \pm 0.1$ & $2.3 \pm 0.0$ & $\begin{array}{l}1.1 \pm 0.9 \\
\mathrm{~b}\end{array}$ & $6.5 \pm 0.1$ & $6.2 \pm 0.3$ & $6.9 \pm 0.0$ & $4.5 \pm 0.1$ & $\begin{array}{l}6.0 \pm 0.9 \\
\mathrm{a}\end{array}$ \\
\hline
\end{tabular}

TTA, total titratable acidity

Means \pm standard deviations of triplicate independent experiments are shown.

Within each row, overall means with different superscript letters are significantly different $(P<0.05)$. 
Table 2. Profiles of volatile organic compounds (VOCs) in two batches of ready-to-eat cacholeira blood sausages (summer and autumn production)

\begin{tabular}{|c|c|c|c|c|c|}
\hline No. & Compounds & $\begin{array}{c}\text { Batch 1 } \\
\text { Summer production } \\
(\mathrm{A} \% \pm \mathrm{SD})\end{array}$ & $\begin{array}{c}\text { Batch } 2 \\
\text { Autumn production } \\
(\mathrm{A} \% \pm \text { SD) }\end{array}$ & Odor notes $\#$ & Origin \\
\hline & Adehydes & & & & \\
\hline 1 & 2-methylbutanal & $0.35 \pm 0.09$ & $0.24 \pm 0.06$ & $\begin{array}{l}\text { Bitter cheese, fruity, caramel, } \\
\text { rancid, malty }\end{array}$ & aa acid catabolism (val, leu, isoleu) \\
\hline 2 & 3-methylbutanal & $0.99 \pm 0.27$ & $0.69 \pm 0.26$ & $\begin{array}{l}\text { bitter cheese, fruity, rancid, } \\
\text { cured ham, malty }\end{array}$ & aa acid catabolism (val, leu, isoleu) \\
\hline 3 & Hexanal & $0.3 \pm 0.03$ & $0.22 \pm 0.11$ & $\begin{array}{l}\text { vegetables, fresch-cut grass, } \\
\text { greem }\end{array}$ & lipid autooxidation \\
\hline 4 & 2-Heptenal & $0.1 \pm 0.04$ & $0.21 \pm 0.07^{*}$ & rancid, dirty & lipid autooxidation \\
\hline \multirow[t]{2}{*}{5} & 5-methylfurfural & $0.58 \pm 0.13^{*}$ & $0.23 \pm 0.15$ & caramellic & maillard reaction \\
\hline & Ketones & & & & \\
\hline 6 & Acetoin & $0.56 \pm 0.07$ & $0.59 \pm 0.34$ & slight buttery & carbohydrate metabolism \\
\hline 7 & 2,3-Octanedione & $0.06 \pm 0.01^{*}$ & $0.04 \pm 0.01$ & green, spicy, fatty, leafy & lipid beta oxidation \\
\hline 8 & 2-methyl-Cyclopentanone & $0.43 \pm 0.17^{*}$ & $0.17 \pm 0.09$ & & wood smoke \\
\hline 9 & 3-methyl-2-Cyclopenten-1-one & $1.23 \pm 0.15^{*}$ & $0.4 \pm 0.19$ & & wood smoke \\
\hline 10 & 2,3-dimethyl-2-Cyclopenten-1-one & $1.14 \pm 0.56^{*}$ & $0.39 \pm 0.06$ & & wood smoke \\
\hline 11 & $\begin{array}{l}\text { 2-hydroxy-3-methyl-2- } \\
\text { Cyclopenten-1-one }\end{array}$ & $0.76 \pm 0.07^{*}$ & $0.49 \pm 0.16$ & & wood smoke \\
\hline \multirow[t]{2}{*}{12} & 2,3-dihydro-1-indanone & $0.13 \pm 0.02^{*}$ & $0.07 \pm 0.02$ & & wood smoke \\
\hline & Esters & & & & \multirow{17}{*}{$\begin{array}{l}\text { microbial metabolism, esterification } \\
\text { of alchols and acids }\end{array}$} \\
\hline 13 & Ethyl Acetate & $11.57 \pm 0.85^{*}$ & $9.02 \pm 1.24$ & synthetic fruity, sweet, fruity & \\
\hline 14 & 2-methylpropanoate & $0.87 \pm 0.21$ & $0.51 \pm 0.59$ & & \\
\hline 15 & ethyl butanoate & $2.14 \pm 0.30$ & $1.9 \pm 0.41$ & $\begin{array}{l}\text { fruity, caramel, pineapple, } \\
\text { strawberry }\end{array}$ & \\
\hline 16 & ethyl 2-methylbutanoate & $0.91 \pm 0.10$ & $1.19 \pm 0.32$ & $\begin{array}{l}\text { sweet, pineapple, fruity, } \\
\text { strawberry }\end{array}$ & \\
\hline 17 & Ethylisovalerate & $0.99 \pm 0.10$ & $1.38 \pm 0.23^{*}$ & sour, pungent, fruity, floral & \\
\hline 18 & Isoamylacetate & $0.84 \pm 0.08^{*}$ & $0.44 \pm 0.15$ & sweet, fruity, banana & \\
\hline 19 & ethyl pentanoate & $0.75 \pm 0.21^{*}$ & $0.36 \pm 0.15$ & fruity, strawberry & \\
\hline 20 & ethyl hexanoate & $1.52 \pm 0.27^{*}$ & $0.41 \pm 0.66$ & pear, sweet, fruity, cherry & \\
\hline 21 & ethyl heptanoate & $0.34 \pm 0.14$ & $0.25 \pm 0.25$ & fruity, pineapple, cognac, rum & \\
\hline 22 & Ethyl lactate & $1.73 \pm 0.40$ & $1.62 \pm 0.30$ & sharp, tart, fruity, buttery & \\
\hline 23 & ethyl-2-hydroxy-butanoate & $0.26 \pm 0.05^{*}$ & $0.08 \pm 0.06$ & & \\
\hline 24 & ethyl octanoate & $1.64 \pm 0.48$ & $1.72 \pm 0.52$ & $\begin{array}{l}\text { fruity, greasy, green, toasted } \\
\text { meat }\end{array}$ & \\
\hline 25 & ethyl decanoate & $1.73 \pm 0.25$ & $1.6 \pm 0.42$ & fruity, citric & \\
\hline 26 & ethyl benzoate & $0.73 \pm 0.07$ & $0.82 \pm 0.37$ & fruity, dry, musty, sweet & \\
\hline 27 & ethyl dodecanoate & $0.76 \pm 0.19$ & $0.35 \pm 0.41$ & $\begin{array}{l}\text { sweet, waxy, floral, soapy, } \\
\text { clean }\end{array}$ & \\
\hline \multirow[t]{2}{*}{28} & ethyl hexadecanoate & $0.08 \pm 0.03$ & $0.07 \pm 0.02$ & $\begin{array}{l}\text { waxy, fruity, creamy, milky, } \\
\text { balsamic }\end{array}$ & \\
\hline & Alcohols & & & & \multirow{8}{*}{$\begin{array}{l}\text { microbial metabolite } \\
\text { microbial metabolite } \\
\text { smoke, from wood smoke } \\
\text { smoke, from wood smoke }\end{array}$} \\
\hline 29 & Ethyl alcohol & $15.5 \pm 1.05$ & $32.07 \pm 10.87^{*}$ & baker's bread, yeast & \\
\hline 30 & isoamyl alcohol & $1.3 \pm 0.10$ & $2.88 \pm 1.26^{*}$ & fermented, fruity, banana & \\
\hline 31 & 2-ethylhexanol & $1.19 \pm 0.95$ & $0.9 \pm 0.54$ & sweet, fatty, fruity & \\
\hline 32 & 2-Furanmethanol & $2.64 \pm 0.29^{*}$ & $1.5 \pm 0.34$ & musty, sweet, caramel, bread & \\
\hline 33 & 2-Furanmethanol, 5-methyl- & $0.47 \pm 0.03$ & $0.45 \pm 0.09$ & & \\
\hline 34 & Benzyl Alcohol & $0.57 \pm 0.05$ & $0.73 \pm 0.15$ & floral rose phenolic balsamic & \\
\hline \multirow[t]{2}{*}{35} & Benzene ethanol & $0.49 \pm 0.2$ & $0.88 \pm 0.16^{*}$ & rose floral & \\
\hline & Terpenoids & & & \multirow{11}{*}{$\begin{array}{l}\text { herbal fresh pine woody } \\
\text { woody green herbal } \\
\text { pungent } \\
\text { woody balsam } \\
\text { lemon, fruity, green } \\
\text { menthol, herbal. Fresh, citric, } \\
\text { orange } \\
\text { herbal } \\
\text { fresh citrus woody spicy } \\
\text { sweet woody spice clove } \\
\text { woody cedar sweet fresh }\end{array}$} & \multirow{11}{*}{ spices } \\
\hline 36 & Alpha-pinene & $0.17 \pm 0.02$ & $0.34 \pm 0.14^{*}$ & & \\
\hline 37 & thujene & $0.1 \pm 0.01$ & $0.15 \pm 0.04^{*}$ & & \\
\hline 38 & BETA-PINENE & $1.63 \pm 0.23$ & $2.3 \pm 0.36^{*}$ & & \\
\hline 39 & Sabinene & $0.16 \pm 0.02$ & $0.22 \pm 0.05$ & & \\
\hline 40 & alpha-Phellandrene & $0.47 \pm 0.26$ & $0.53 \pm 0.25$ & & \\
\hline 41 & limonene & $0.19 \pm 0.1$ & $0.29 \pm 0.12$ & & \\
\hline 42 & gamma-Terpinene & $3.37 \pm 0.57$ & $4.01 \pm 2.01$ & & \\
\hline 43 & cymol & $4.45 \pm 0.68$ & $5.45 \pm 0.75$ & & \\
\hline 44 & Caryophyllene & $1.08 \pm 0.15$ & $1.48 \pm 0.30^{*}$ & & \\
\hline \multirow[t]{2}{*}{$\begin{array}{l}44 \\
45\end{array}$} & alpha cedrene & $0.32 \pm 0.43$ & $0.71 \pm 0.16$ & & \\
\hline & Acids & & & & \\
\hline 46 & Acetic acid & $11.73 \pm 3.1$ & $7.64 \pm 2.99$ & vinegar, sharp, sour & carbohydrate metabolism \\
\hline 47 & Propanoic acid & $0.81 \pm 0.07^{*}$ & $0.31 \pm 0.16$ & slight sour, sweaty, cheese & lipid auto oxidation \\
\hline 48 & Butanoic acid & $0.94 \pm 0.19^{*}$ & $0.47 \pm 0.12$ & strong cheese, sweaty & carbohydrate metabolism \\
\hline 49 & Hexanoic acid & $0.74 \pm 0.32$ & $0.64 \pm 0.25$ & sweaty, rotten & lipid auto oxidation \\
\hline 50 & Octanoic acid & $1.47 \pm 1.25$ & $1.03 \pm 0.41$ & rancid, wood, toasted & lipid auto oxidation \\
\hline 51 & Decanoic acid & $0.21 \pm 0.04$ & $0.19 \pm 0.02$ & pungent & lipid auto oxidation \\
\hline
\end{tabular}




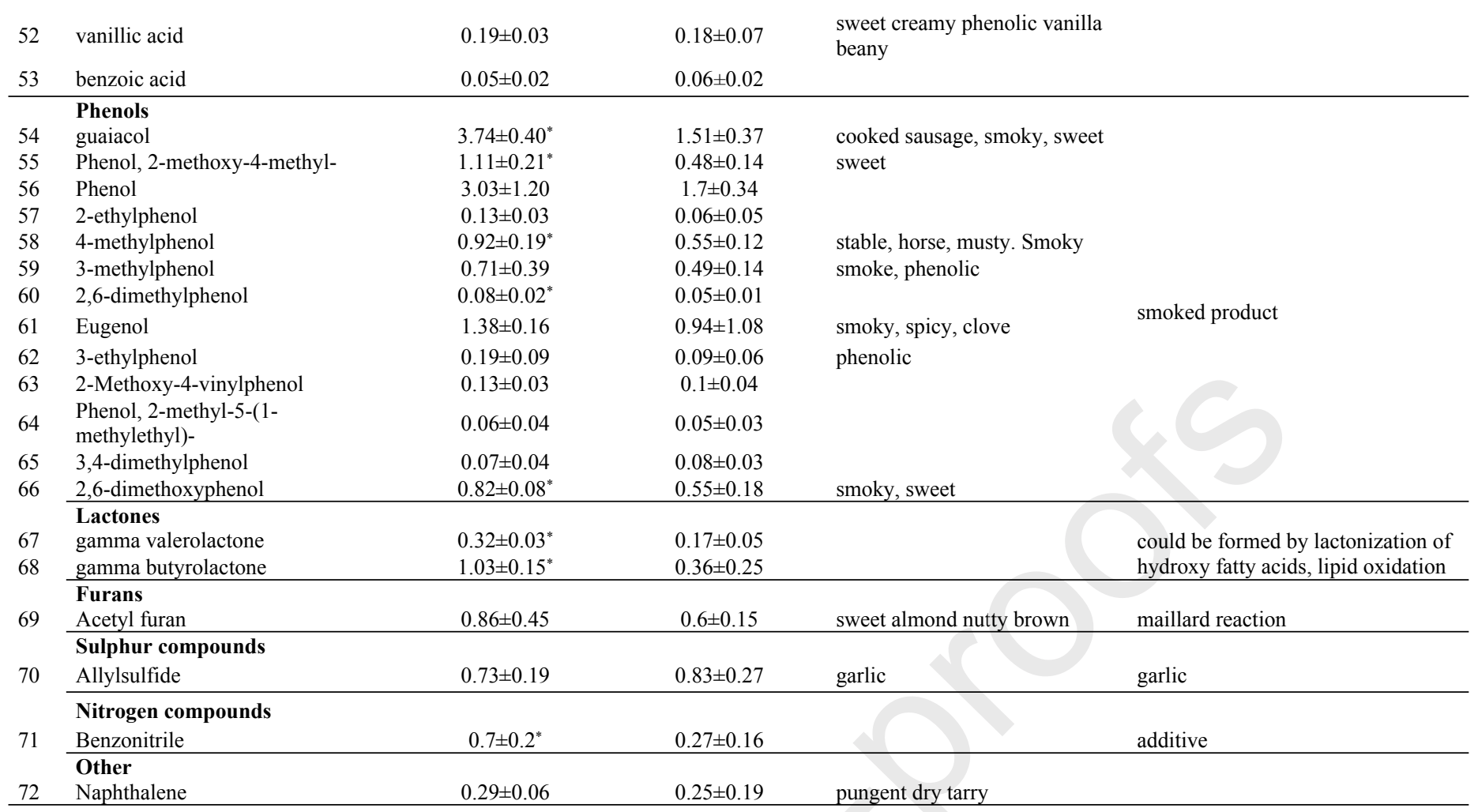

\# based on online databases (www.flavornet.org, and www.thegoodscentscompany.com).

Results are reported as A\%=Area Peak Compound/Area Peak Total Compounds $) \times 100(\mathrm{~A} \% \pm \mathrm{SD})$

Results for summer and autumn production derived from an average of C1-C4 and C5-C8 samples, respectively.

Symbol * indicates significant differences $(p<0.05)$ in relative volatile compounds among the two different summer and autumn productions. 


\section{Highlights}

- Microbiota and VOCs of cacholeira blood sausage were investigated

- A simple bacterial composition dominated by Lactobacillus sakei was highlighted

- Debaryomyces hansenii and Starmerella apicola dominated the fungal population

- A seasonal effect on the mycobiota diversity was hypothesized

- VOCs included esters, phenols, terpenoids, acids, alcohols, ketones and aldehydes 